\title{
Sildenafil: from angina to erectile dysfunction to pulmonary hypertension and beyond
}

\section{Hossein A. Ghofrani*, Ian H. Osterloh ${ }^{\ddagger}$ and Friedrich Grimminger*}

Abstract | In less than 20 years, the first selective type 5 phosphodiesterase inhibitor, sildenafil, has evolved from a potential anti-angina drug to an on-demand oral treatment for erectile dysfunction (Viagra), and more recently to a new orally active treatment for pulmonary hypertension (Revatio). Here we describe the key milestones in the development of sildenafil for these diverse medical conditions, discuss the advances in science and clinical medicine that have accompanied this journey and consider possible future indications for this versatile drug.

\section{Angina pectoris \\ Severe chest pains caused by insufficient supply of blood to the heart. \\ Tachyphylaxis \\ Reduced responsiveness to a drug that is chronically supplied and requires dose up-titration to maintain the same level of efficacy over time.}

\footnotetext{
${ }^{*}$ Medical Clinic IIIV, Department of Internal Medicine, University Hospital Giessen and Marburg, $\mathrm{GmbH}$, Klinikstrasse 36, 35392 Giessen, Germany. ‡Pfizer Ltd (ipc 383), Ramsgate Road, Sandwich, Kent CT13 9NJ, UK. Correspondence to H.A.G. e-mail: ardeschir.ghofrani@uglc.de doi: $10.1038 /$ nrd2030
}

\section{Origins of the cGMP/PDE5 project at Pfizer}

In the mid-1980s, a very active cardiovascular research programme was based at the Pfizer European research laboratories in Sandwich, UK. Already discovered and under clinical development at Sandwich were various vasodilators, including prazosin (Minipress), doxazosin (Cardura) and amlodipine (Norvasc), which would become well-known products marketed for the treatment of cardiovascular diseases, primarily hypertension. There was also an active clinical development programme investigating the therapeutic potential of modulating cyclic adenosine monophosphate (cAMP) levels by selective inhibition of phosphodiesterase type 3 (PDE3) for the treatment of heart failure.

At this time, the Pfizer biologists also began to consider the therapeutic possibilities that might arise from modulating intracellular levels of cyclic guanosine monophosphate (cGMP). Nitrates were and still are in widespread clinical use for the treatment of cardiovascular conditions, particularly angina pectoris ${ }^{1}$. Nitrates are an exogenous source of nitric oxide (NO), a labile gas that can diffuse across cell membranes into vascular smooth muscle cells and stimulate the action of soluble guanylate cyclase to convert guanosine triphosphate (GTP) to $\mathrm{cGMP}^{2}$. The formation of cGMP then initiates a cascade of reactions that ultimately decreases intracellular calcium levels, thereby promoting relaxation of the smooth muscle ${ }^{3,4}$. Therefore nitrates, via their relaxant effects on vascular smooth muscle, act as mixed dilators of arteries and veins. The resulting decrease in peripheral vascular resistance and cardiac preload, coupled with improved perfusion of ischaemic areas of the myocardium, leads to a clinically useful anti-anginal effect.
However, the therapeutic potential of nitrates is limited by the rapid induction of tachyphylaxis with prolonged administration ${ }^{5}$. This limitation led some scientists at Pfizer to consider alternative approaches to modulate NO signalling.

\section{PDE5 is selected as a target}

Although the precise mechanism of tolerance to nitrates is not clear, any treatment that does not directly increase NO levels might circumvent this problem. The scientific team at Pfizer therefore proposed that a downstream target in the NO/cGMP pathway could be modulated. Cyclic nucleotides (cAMP and cGMP) are degraded by intracellular PDEs (FIG. 1). In the mid-1980s, five subtypes of PDEs were identified. PDE3 and PDE4 specifically catalyse the breakdown of CAMP, whereas PDE1 and PDE2 catalyse the breakdown of both cAMP and cGMP. The fifth member of this group, PDE5, exclusively catalyses the breakdown of cGMP (TABLE 1). PDE5 is present in the smooth muscle of the systemic vasculature, and in platelets. Studies by Corbin et al. revealed that the regulatory domain in the amino-terminal portion of PDE5 contains a phosphorylation site (serine 92), two allosteric cGMP-binding sites, $a$ and $b$, and at least a portion of the dimerization domain. The catalytic domain in the carboxy-terminal portion of the protein contains the two $\mathrm{Zn}^{2+}$-binding motifs $\mathrm{A}$ and $\mathrm{B}$, and a cGMP substratebinding $\operatorname{site}^{6}$ (FIG. 2). In 1986 Pfizer formed a project team of scientists at Sandwich, with the aim of developing a selective inhibitor of PDE5 and evaluating its preclinical pharmacology (TIMELINE). Eventually the team succeeded in synthesizing novel pyrazolopyrimidines that were highly potent inhibitors of PDE5. A compound 


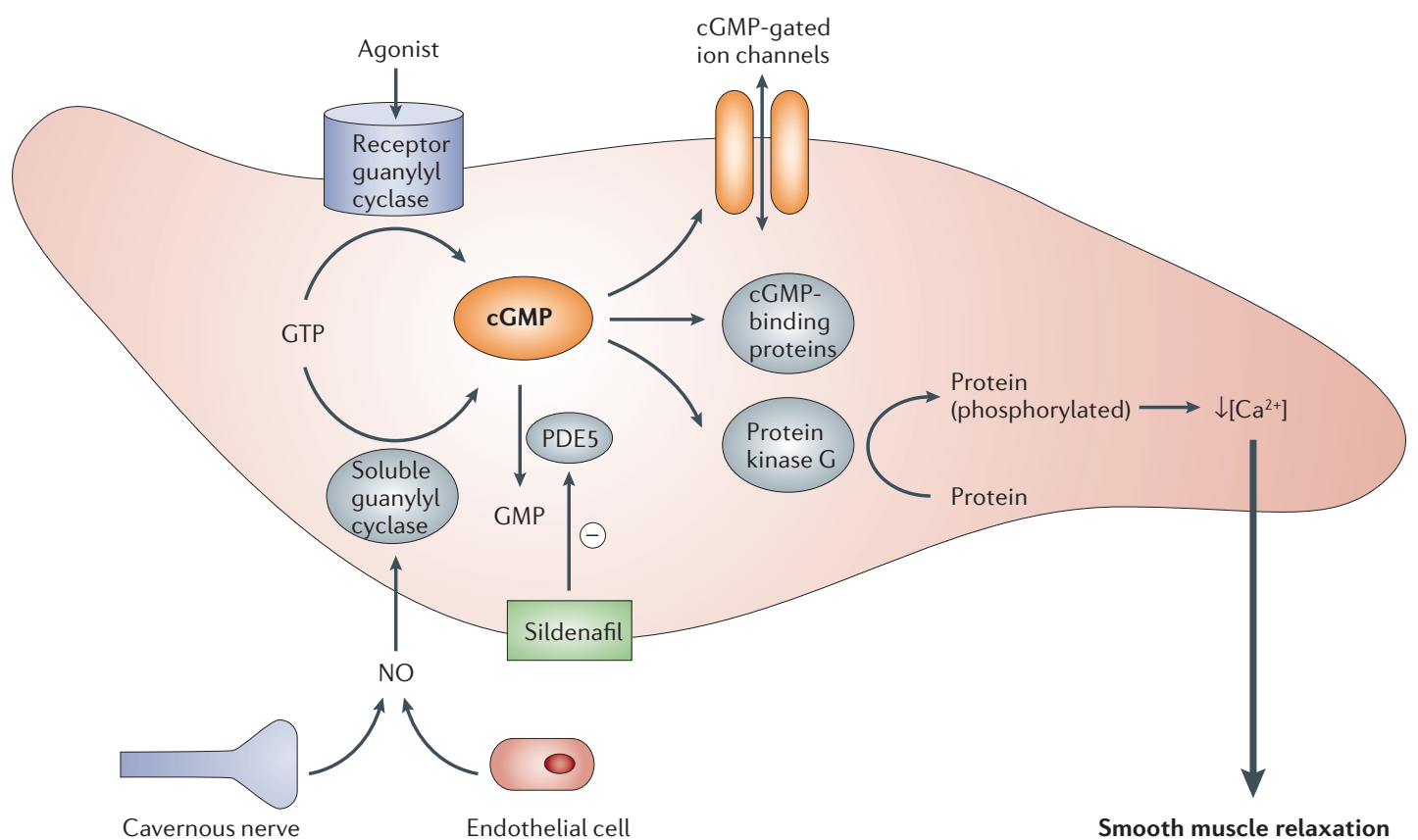

Figure 1 | The NO/cGMP signalling pathway. The figure shows stimuli promoting the synthesis of cGMP, downstream intracellular signalling targets modulated by cGMP and the role of phosphodiesterases (PDEs) in cGMP breakdown. This pathway mediates relaxation of vascular smooth muscle and penile erection (only upon sexual stimulation) and pulmonary vasodilatation (continuously). Smooth muscle relaxation is in part mediated via protein kinase G (PKG) activation, subsequent potassium channel opening and reductions in intracellular calcium levels ${ }^{83}$. PDE5 is the target for sildenafil and other PDE5 inhibitors in the treatment of chronic vascular disorders. cGMP, cyclic guanosine monophosphate; GMP, guanosine monophosphate; GTP, guanosine triphosphate; NO, nitric oxide.

designated chemically as 1-[[3-(6,7-dihydro-1-methyl7-oxo-3-propyl-1H-pyrazolo[4,3-d]pyrimidin-5-yl)4-ethoxyphenyl] sulphonyl]-4-methylpiperazine, was chosen for further profiling (FICS 3,4). It was initially named UK-92,480, but is now better known as sildenafil, of which the citrate salt is marketed under the trade name Viagra. The compound was demonstrated to have very good potency ( $\mathrm{an} \mathrm{IC}_{50}$ of $3.5 \mathrm{nM}$ against PDE5 derived from human platelets), and excellent selectivity over PDEs 1-4 (REF. 7). Moreover, in preclinical studies, this compound displayed vasodilatory effects, abrogated platelet aggregation ${ }^{8}$, and inhibited thrombus reformation in a damaged carotid artery (modified Folt's model). Therefore, in 1989 UK-92,480 was selected to undergo further development and eventually entered clinical trials in 1991 (REF. 9).

\section{Clinical development programme for angina}

In 1991 studies in healthy volunteers commenced, in which single doses of UK-92,480 up to $200 \mathrm{mg}$ were administered. UK-92,480 had a relatively short plasma half-life $(\sim 4 \text { hours })^{10}$. The doses were generally well tolerated and, at moderate and higher doses, modest reductions in systemic blood pressure and side effects associated with vasodilatation (such as headache and flushing) were observed. At doses of $150 \mathrm{mg}$ and higher, transient disturbances in colour vision perception were reported (later in the development programme, these were demonstrated to be caused by a weak inhibitory effect of UK-92,480 on PDE6 in photoreceptors $)^{11}$.
Subsequently, in a study involving intravenous administration of UK-92,480, a moderate vasodilatory effect was observed in patients with angina. A later study in healthy volunteers that was designed to investigate a potential pharmacodynamic interaction between UK-92,480 and glyceryl trinitrate (GTN) demonstrated that UK-92,480 augmented the vasodilatory and antihypertensive effects of $\mathrm{GTN}^{12}$. Although this finding was positive in confirming the mode of action of sildenafil in a clinical setting, it was also potentially problematic. UK-92,480 would have to be contraindicated in patients taking nitrates or, alternatively, a safe way of co-administering the two different agents needed to be developed and demonstrated.

In 1992, several multiple-dose, healthy volunteer studies were undertaken to investigate the pharmacokinetics, pharmacodynamics and tolerance of UK-92,480. When administered at doses of up to $75 \mathrm{mg}$ three times per day for 10 consecutive days, some volunteers reported headaches, flushing, indigestion and muscle aches. Some volunteers also reported penile erections as a side effect. Initially this was not considered to be of major significance, because the volunteers were reporting these effects after a mere several days of UK-92,480 administration. Therefore, cardiovascular indications remained the primary focus of ongoing clinical investigations during 1992 and 1993. However, by mid-1993, UK-92,480 was looking less promising as a new treatment for angina pectoris. The relatively short half-life indicated that treatment would have to be administered at least three times per day for the chronic treatment of 


\section{Table 1 | PDE nomenclature and families}

\begin{tabular}{|lll|}
\hline PDE family & Subfamily (number of splice variants) & Substrate \\
\hline 1 & $\mathrm{~A}(4), \mathrm{B}(1), \mathrm{C}(5)$ & cAMP/cGMP \\
\hline 2 & $\mathrm{~A}(3)$ & $\mathrm{cAMP} / \mathrm{cGMP}$ \\
\hline 3 & $\mathrm{~A}(1), \mathrm{B}(1)$ & $\mathrm{cAMP} / \mathrm{cGMP}$ \\
\hline 4 & $\mathrm{~A}(8), \mathrm{B}(3), \mathrm{C}(4), \mathrm{D}(5)$ & $\mathrm{cAMP}$ \\
\hline 5 & $\mathrm{~A}(3)$ & $\mathrm{cGMP}$ \\
\hline 6 & $\mathrm{~A} \mathrm{(1),B} \mathrm{(1),} \mathrm{C} \mathrm{(1)}$ & $\mathrm{cGMP}$ \\
\hline 7 & $\mathrm{~A}(3), \mathrm{B}(1)$ & $\mathrm{cAMP}$ \\
\hline 8 & $\mathrm{~A}(5), \mathrm{B}(1)$ & $\mathrm{cAMP}$ \\
\hline 9 & $\mathrm{~A}(6)$ & $\mathrm{cGMP}$ \\
\hline 10 & $\mathrm{~A} \mathrm{(2)}$ & $\mathrm{cAMP} / \mathrm{cGMP}$ \\
\hline 11 & $\mathrm{~A}(4)$ & $\mathrm{cAMP} / \mathrm{cGMP}$ \\
\hline
\end{tabular}

cAMP, cyclic adenosine monophosphate; cGMP, cyclic guanosine monophosphate; PDE, phosphodiesterase.

Corpus cavernosum An expandable erectile tissue along the length of the penis, which fills with blood during male erection. angina. The demonstrated interaction with nitrates was also a factor complicating future drug development for cardiovascular indications.

\section{Thoughts turn to erectile dysfunction}

During the 1980s, advances were made in the recognition and treatment of erectile dysfunction (ED). Prior to then, many clinicians considered ED to be either a relatively trivial issue and/or a condition that was predominantly attributable to psychological causes. However, urologists interested in ED had started treating their patients with intracavernosal injections of vasodilating drugs (for example, papaverine and prostaglandin E1) that functioned by modulating levels of cAMP. This pharmacological approach worked for many patients, but drawbacks included the invasive nature of the treatment, the induction of an 'artificial' erection that would often last long after intercourse had finished, with the added risks of local bleeding, bruising and priapism (a prolonged painful erection lasting longer than 6 hours). There was no doubt that an effective oral agent would be a major breakthrough in the treatment of this distressing condition, although at the time few researchers and clinicians in the field thought this was possible.

The decision to undertake pilot studies with sildenafil in ED was supported by the observation that penile erections were a common side effect in the multipledose sildenafil Phase I study. Furthermore, emerging data implicated $\mathrm{NO}$ as a key mediator of the neural and haemodynamic effects that lead to penile erection in men. In particular, in the early 1990s, Ignarro and others reported that NO is the neurotransmitter that is released from cavernous nerves during sexual stimulation. The NO diffuses into vascular smooth muscle cells of the penis, stimulating the production of cGMP and leading to corpus cavernosum smooth muscle relaxation, vasocongestion, veno-occlusion (by constriction of the venous outflow from the penis against the tunica albuginea) and, ultimately, erection ${ }^{13-15}$. Local neural production of high quantities of NO in the presence of sexual stimulation enables selective vasodilatation of the penile vasculature. The Pfizer team postulated that the administration of an inhibitor of cGMP breakdown would enhance and prolong the vasodilatory response, but only during sexual stimulation. The prospect of an oral agent that could work naturally with sexual stimulation to facilitate and maintain erections, without causing excessive vasodilatation in the systemic vasculature, was indeed an exciting prospect.

Clinical studies in erectile dysfunction. In late 1993 the first clinical study in patients with ED was undertaken using a very novel trial design. In order to overcome the practical problem of confirming an erectogenic effect while allowing the patients to be sexually stimulated, a Rigiscan device that contains two loops that are placed round the base and tip of the penis was used to monitor and record the girth and hardness of the penis during sexual stimulation. In order to maximize the chances of detecting a signal, the patients selected for the first two studies were relatively healthy men with ED but no clinically apparent cardiovascular diseases or other underlying risk factors. By mid-1994, after completion of two separate clinical studies, single doses of sildenafil were shown to enhance erectile responses to sexual stimulation and to be well tolerated ${ }^{16}$; moreover, a clear dose-response relationship was observed ${ }^{16}$.

After this initial success, a full development programme was designed. Again, novel clinical trial designs (including the development of a new instrument, the International Index of Erectile Function ${ }^{17}$ ) were used. Sildenafil was effective in almost all types of patients with $\mathrm{ED}^{18-21}$, including those with diabetes mellitus ${ }^{22,23}$, cardiovascular disease ${ }^{24}$, multiple sclerosis ${ }^{25}$, spinal cord injury ${ }^{26}$ and even in patients who had undergone radical prostatectomy ${ }^{27}$. Efficacy response rates of $70 \%$ or higher were consistently observed in clinical trials, although response rates were somewhat lower in postprostatectomy patients $(\sim 40-50 \%)$ and those with diabetes mellitus ( $\sim 60 \%)$. Sildenafil was very well tolerated when taken on demand (usually about twice per week) and muscle aches were very rarely reported in the Phase IIb/III programme ${ }^{28}$.

During and after the full development programme, a further six families of PDE (PDEs 6-11) were identified (TABLE 2). The activity of sildenafil was assessed against representative members of all of these PDE families. Sildenafil exhibited excellent selectivity over PDEs 7-11, but only about tenfold selectivity for PDE5 versus PDE6 $^{29}$. Subsequent in vitro and in vivo investigations confirmed that the transient visual side effects observed with sildenafil treatment were almost certainly due to weak inhibition of PDE6, a cGMP-metabolizing enzyme that is present exclusively in photoreceptors. Sildenafil was shown to have similar potency against PDE6 in all species routinely evaluated in toxicological screens, and it was further demonstrated that long-term sustained inhibition of PDE6 by sildenafil (even at doses many times greater than those administered to humans) did not lead to any lasting damage to the structure and function of the eye $\mathrm{e}^{30-32}$. 


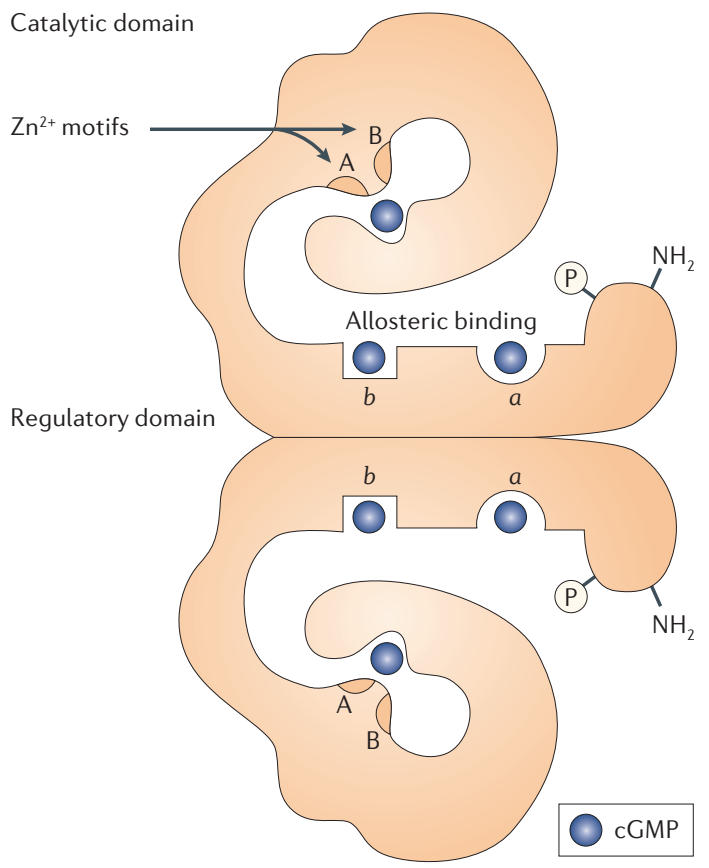

Figure 2 | Working model of PDE5. The regulatory domain in the amino-terminal portion of PDE5 contains a phosphorylation site and two allosteric cGMP-binding sites, $a$ and $b$, that are theorized to be involved in a cGMP negative-feedback loop. The catalytic domain in the carboxyl-terminal portion contains two $\mathrm{Zn}^{2+}$-binding motifs, $A$ and $B$, and a cGMP-binding substrate site. cGMP, cyclic guanosine monophosphate; PDE5, phosphodiesterase type 5 . Reproduced, with permission, from REF. 6 (c) (1999) American Society for Biochemistry and Molecular Biology.

Registration and marketing of Viagra for ED. By 1997 more than 4,500 subjects had been exposed to sildenafil, and 21 separate clinical trials had demonstrated the efficacy of sildenafil in various patient populations ${ }^{16-21}$. The main dose-related side effects were transient headache, flushing, indigestion and disturbances in colour vision. Nitrates were contraindicated. Pfizer submitted registration dossiers to both the FDA and the European Medicines Evaluation Agency (EMEA). The FDA approved Viagra for the treatment of men with ED in March 1998. European approval followed in September 1998.

The introduction of Viagra to the market revolutionized the treatment of ED, and within a few weeks of the introduction of Viagra to the US market more than one million patients had received prescriptions for sildenafil. The first-line treatment of ED began to move from specialists, such as urologists and psychiatrists, to a general practice setting. During 1998, spontaneous case reports of myocardial infarction, stroke and sudden death were reported (sometimes in association with sexual activity). However, an extensive number of investigative clinical trials and epidemiological studies have been undertaken since 1998, and none have provided any evidence that sildenafil provokes myocardial infarction or stroke when used in accordance with the prescribing instructions $s^{33-37}$.
Indeed there are now multiple scientific papers suggesting a potential utility of sildenafil in protecting the ischaemic myocardium and in treating stroke $\mathrm{e}^{38-45}$.

There have also, since 2000, been occasional case reports ${ }^{46-49}$ of non-arteritic anterior ischaemic optic neuropathy (NAION) in patients taking sildenafil. Although NAION is the most common acute optic neuropathy in people older than 50 years it is a relatively rare event causing partial visual loss in one eye, and is associated with various risk factors, including cardiovascular disease and a small cup:disk ratio. In a recently published review of clinical trial data ${ }^{50}$, Gorkin et al. estimated an incidence of 2.8 cases of NAION per 100,000 patientyears of sildenafil exposure, which is similar to estimates reported in the general US population (2.5-11.8 cases per 100,000 men aged $>50$ years $)^{51,52}$. Very recently the original authors of many of these case reports published a further review ${ }^{53}$ and concluded that most of the case reports of NAION might be an expected coincidence because sildenafil is a top-selling medication and patients who receive the drug are frequently older, vasculopathic and already at risk of NAION. They further conclude that the only patients who need to avoid PDE5 inhibitors for visual reasons are those who have previously suffered NAION in one eye.

At the time of preparing this paper, sildenafil has been on the market as a treatment for ED for more than 7 years. It is now estimated that more than 750,000 physicians have prescribed sildenafil to over 23 million men, and sildenafil remains by far the most widely used treatment for $\mathrm{ED}^{54}$. Preclinical and clinical investigations continue to add to our knowledge with respect to the mode of action of sildenafil in treating ED, the full scope of ED patients amenable to treatment with sildenafil and the potential for the management of other indications. Post-marketing studies have revealed that conjunctival injection and epistaxis are relatively rare side effects of sildenafil administration. Contraindications have been extended to include left ventricular outflow obstruction, multiple system atrophy, and additional caution is necessary if patients are receiving alpha-blockers.

\section{Thoughts turn to pulmonary hypertension}

After the approval of sildenafil for the treatment of ED, thoughts started to turn to other potential indications for this drug. Sanchez et al..$^{55}$ observed upregulation of PDE5 gene expression in pulmonary hypertensive lungs. Furthermore, it was observed that zaprinast ( $M \& B$ 22948), E4021 and dipyridamole (a relatively nonselective PDE inhibitor with PDE5-inhibitory activity) could ameliorate pulmonary pressure in experimental pulmonary hypertension models ${ }^{56-60}$. With the availability of the more potent and selective PDE5 inhibitor sildenafil, a series of preclinical and clinical investigations were conducted to examine the therapeutic potential of this approach in pulmonary vascular diseases. The first intravenous placebo control study (Pfizer study 1024) was conducted to evaluate the effect of intravenous administration of sildenafil at various doses. The study was conducted between 1998 and 2000, and showed that sildenafil selectively reduced pulmonary pressure and 
Timeline | Milestones in the development of sildenafil for erectile dysfunction and pulmonary hypertension

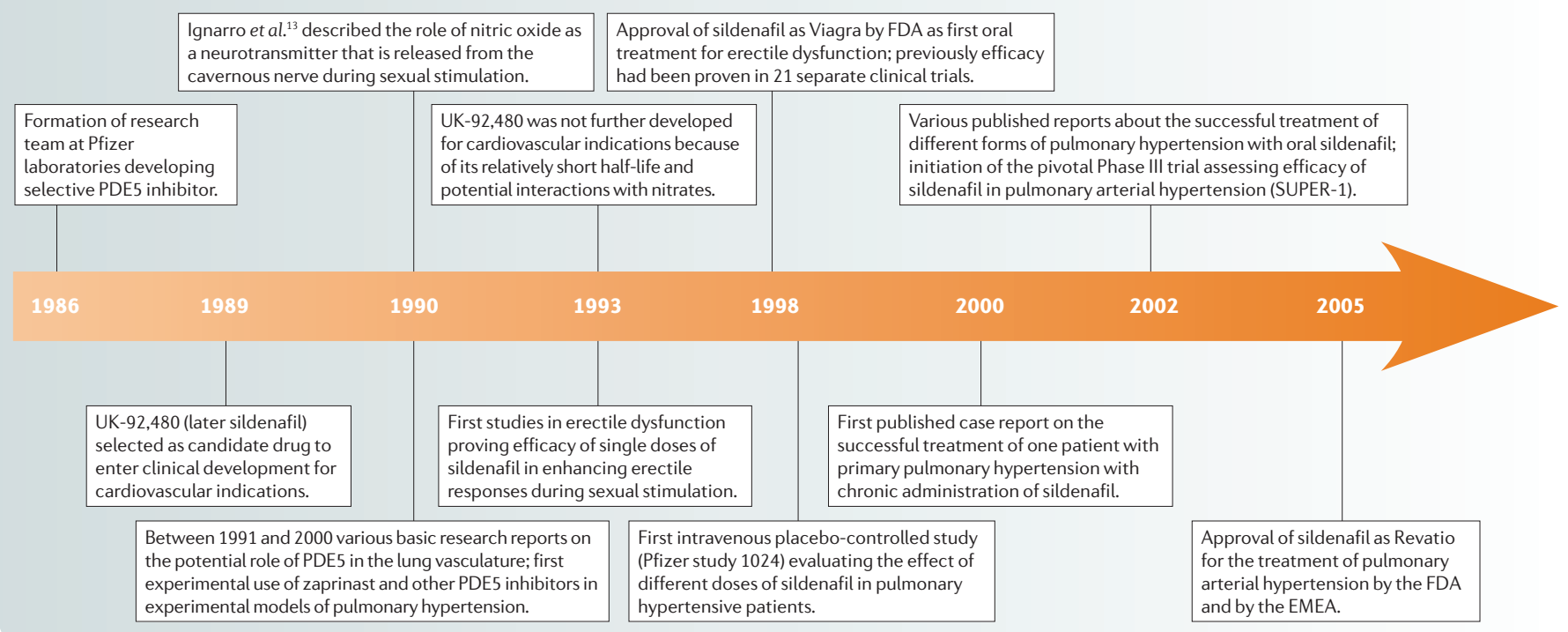

pulmonary vascular resistance in more than 80 patients with pulmonary arterial hypertension, pulmonary venous hypertension and pulmonary hypoxic hypertension. It was also observed that the effect reached a plateau at a plasma concentration of $100 \mathrm{ng}$ per $\mathrm{ml}$ of sildenafil (G. Butrous, personal communication). During this period, interest in the role of sildenafil in pulmonary hypertension gained significant momentum.

Pulmonary hypertension: background. Pulmonary hypertension is a progressive disease of various origins which has a poor prognosis and results in right heart dysfunction ${ }^{61}$. According to the new classification for pulmonary hypertension from the Third World Conference on Pulmonary Hypertension in Venice in 2003 (REF. 62), five subclasses of chronic pulmonary hypertension can be defined. Among these groups, class 1 represents the so-called pulmonary arterial hypertension (PAH) group, which includes a mixture of diseases that have some pathophysiological, histological and prognostic features in common. Idiopathic pulmonary arterial hypertension (iPAH, formerly known as primary pulmonary hypertension ( $\mathrm{PPH})$ ) is the most prominent, although exceptionally rare, representative of this class, and is a disease for which loss-of-function mutations in the bone morphogenetic protein type 2 receptor (BMPR2) have been identified as one underlying mechanism ${ }^{63-65}$. Recent randomized controlled trials for drug development in this area have focused on patients suffering from $\mathrm{iPAH}$ as well as associated forms including connective tissue disease-associated pulmonary hypertension and pulmonary hypertension secondary to congenital heart disease ${ }^{66}$.

Previous treatments for pulmonary arterial hypertension. Continuous infusion of prostacyclin was the first licensed treatment for severe pulmonary arterial hypertension, and this approach has been shown to be life-saving ${ }^{67}$ and to improve exercise capacity ${ }^{68}$ in controlled clinical trials. However, there are also drawbacks of this therapy inherent both to the nature of the drug, and to the necessity of implanting a continuous central intravenous line. Preserving the advantageous effects of prostacyclin, while avoiding several of its limitations, the concept of aerosolized iloprost (a long-acting prostacyclin analogue) for the treatment of PAH was developed ${ }^{69,70}$. This therapy is currently approved in the US, Europe and many other countries for the treatment of $\mathrm{PAH}^{71}$; however, its use is cumbersome because of the need for frequent inhalation manoeuvres (six to nine times daily) and elaborate nebulization techniques ${ }^{72}$. The first oral drug approved for the treatment of pulmonary arterial hypertension was the non-selective oral endothelin receptor antagonist bosentan. The efficacy of this therapeutic approach has been proven in randomized controlled trials and led to approval in the US and Europe $e^{73,74}$. However, the long-term use of this vasodilator might be limited by liver toxicity, which affects up to $10 \%$ of all patients treated. Therefore the search for an 'ideal' pulmonary vasodilator that combines high treatment efficacy, pulmonary selectivity, simplicity of administration and reduced side effects continued until the PDE5 inhibitor sildenafil became the focus of investigation.

Role of PDE5 in the pulmonary vasculature. Nitric oxide is constitutively produced in the lung by $\mathrm{NO}$ synthases (NOS). The main enzymatic source of lung NO production is endothelial (or constitutive) NOS (eNOS), which is located in the vascular endothelium and the airway epithelium ${ }^{75,76}$. eNOS-derived NO activates soluble guanylate cyclase, which in turn increases intracellular cGMP levels. Adaptation of the perfusion distribution to well-ventilated areas of the lung (ventilation/perfusion (V/Q) matching) is regulated primarily by local NO production $^{77,78}$, because the most prominent stimulus for 

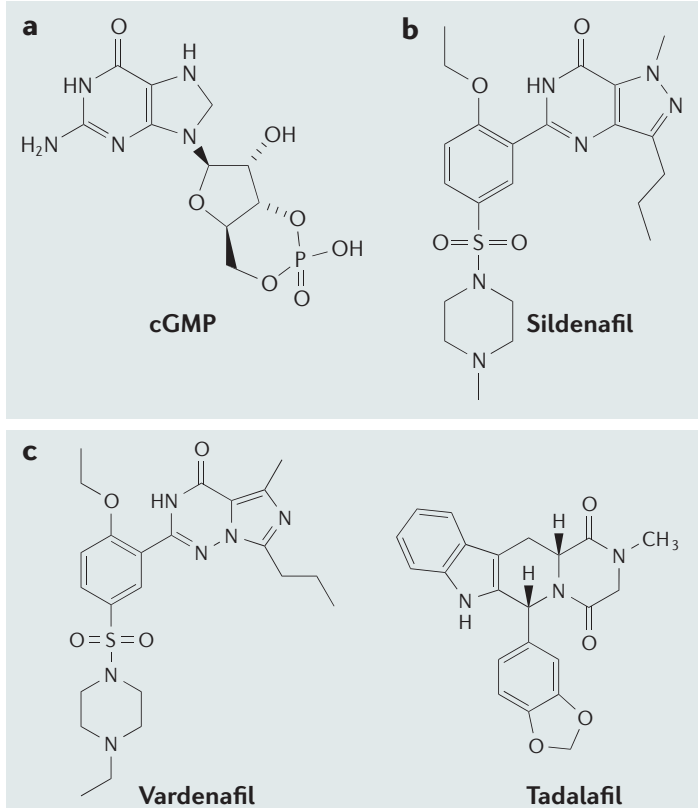

Figure 3 | Comparison of the structures of cGMP, sildenafil and other PDE5 inhibitors. a|The native substrate, cGMP. b | Sildenafil. c | Vardenafil and Tadalafil. cGMP, cyclic guanosine monophosphate; PDE5, phosphodiesterase type 5 .

local NO production in the lung is alveolar distension during inspiration ${ }^{78-82}$. Local NO release therefore results in redirection of blood flow to well-ventilated areas of the lung (V/Q matching, FIG. 5). NOS is regulated at the transcriptional and post-translational levels ${ }^{83}$. The most important cGMP-degrading phosphodiesterase, PDE5, is abundantly expressed in lung tissue ${ }^{84-87}$. When compared with the expression of PDE5 in other tissues such as the myocardium, the expression and activity of PDE5 is considerably higher in lung tissue $\mathrm{e}^{88}$. PDE5 is therefore an ideal target for the pharmacological treatment of vascular disturbances in the pulmonary circulation, including pulmonary arterial hypertension and pulmonary hypertension associated with underlying lung disorders. Moreover, sildenafil is the first oral drug that has the potential to dynamically augment $\mathrm{NO}$-related vasodilatation in regions of perfusion demand, and - in the case of the lung - prevent wasted perfusion (venous admixture) and wasted ventilation (dead space ventilation).

In 1991, Haynes and colleagues demonstrated that the PDE5 inhibitor zaprinast caused a reduction in the vasoconstrictor response of isolated rat lungs to acute alveolar hypoxia ${ }^{89}$. The same compound was shown to induce a selective pulmonary vasodilatation when compared with its effects on the systemic circulation in intact anaesthetized newborn lambs exposed to acute hypoxia ${ }^{90}$, as well as in chronically hypoxic rats ${ }^{91}$. However, in the latter study, the PDE5 inhibitor E4021 turned out to be more selective for pulmonary circulation, without any dilating effects in the systemic circulation at the doses applied. Inhibition of hypoxic pulmonary vasoconstriction (HPV) was also achieved in isolated rabbit lungs by zaprinast ${ }^{80}$.
Investigations with the PDE5 inhibitor sildenafil in isolated perfused rodent lungs demonstrated a marked inhibition of $\mathrm{HPV}^{92,93}$, thereby confirming that PDE5 inhibitors act as potent pulmonary vasodilators. Oral treatment of chronically hypoxic mice with sildenafil prevented the development of pulmonary hypertension ${ }^{92}$. In these studies, Zhao and colleagues also elegantly demonstrated that it was not only eNOS-derived NO that contributed to the effects of the PDE5 inhibitor ${ }^{22}$. The authors suggested the involvement of natriuretic peptides - which increase intracellular cGMP levels via receptor-linked activation of the particulate guanylate cyclase - by showing that in natriuretic peptide receptor A (NPR-A) knockout mice, the anti-remodelling effects of sildenafil on the pulmonary vasculature and the right ventricle were reduced ${ }^{93}$. Although all of the investigations described above involved initiating the treatment of chronically hypoxic animals at the onset of hypoxia, Sebkhi et al. demonstrated that even curative application of sildenafil reduces pulmonary artery pressure and vascular muscularization in the lungs of chronically hypoxic rats ${ }^{94}$.

In essence, these investigations demonstrate that PDE5 inhibition has anti-pulmonary hypertensive effects, with selective effects on the pulmonary vascular resistance. Therefore the selective pulmonary effects of PDE5 inhibitors are most probably attributable to a generally high level of PDE5 in the pulmonary circulation compared with the systemic circulation ${ }^{84,86,88,95}$ and the fact that NO production in the lung is high, akin to the situation in the corpus cavernosum ${ }^{78,82,96,97}$. In a recent publication, Itoh et al. investigated the effect of sildenafil alone, or in combination with beraprost, a prostacyclin analogue, on the development of experimental $\mathrm{PAH}^{98}$. Long-term administration of sildenafil to rats in a monocrotaline model of pulmonary hypertension resulted in a decrease in right ventricular systolic pressure, right heart hypertrophy and medial wall thickness. The curative properties of sildenafil after the development of pulmonary hypertension yielded similar results ${ }^{99}$. Sildenafil reduced pulmonary artery pressure and vascular muscularization in lungs from chronically ill rats, and reduced the expression of matrix metalloproteinases (MMP) 2 and 9. Additionally, the degree of fully muscularized small $(<50 \mu \mathrm{m})$ pulmonary arteries was decreased.

Clinical experience with sildenafil for the treatment of chronic pulmonary hypertension. The vasodilatory effects of inhaled NO are restricted to the pulmonary vasculature. In addition, NO has a very short half-life, is used as a screening agent for lung vasoreactivity ${ }^{100}$, and is effective in improving gas exchange in selected patients with adult respiratory distress syndrome (ARDS) $)^{101}$. Weaning from chronic NO treatment in patients with ARDS was facilitated by oral sildenafil ${ }^{102}$. An initial case report of an adult patient suffering from severe pulmonary arterial hypertension who was treated chronically with very high doses of oral sildenafil indicated that this approach might be effective ${ }^{103}$. In paediatric patients, the administration of intravenous prostacyclin is hampered to a greater extent by problems associated with the mode 


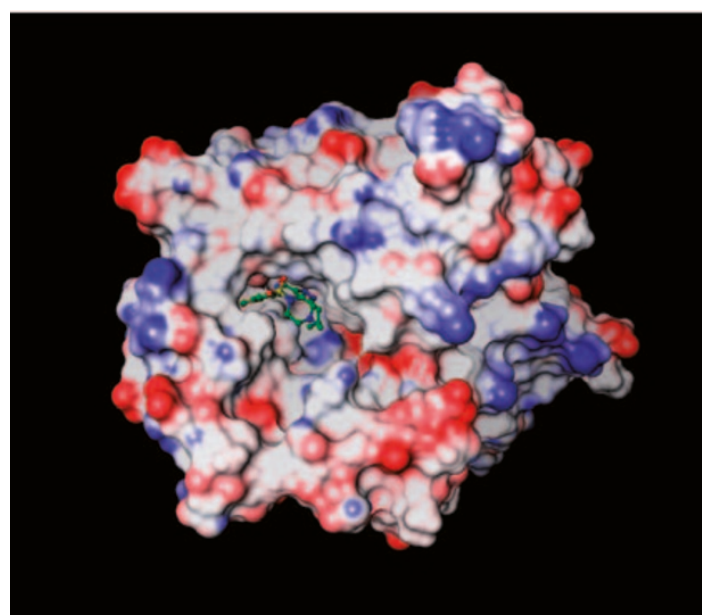

Figure 4 | Structure of the PDE5 catalytic domain.

$\mathrm{X}$-ray crystallography undertaken at the Pfizer Sandwich laboratories has been used to solve the first atomic structure of the PDE5 catalytic domain ${ }^{200,201}$. PDE5 has a globular structure and possesses a deep cleft, the GMPbinding site. The figure illustrates the binding of the UK-92,480 at the catalytic site of PDE5 with a surface representation of the protein coloured according to electrostatic charge. PDE5, phosphodiesterase type 5.

of administration than it is in adult patients. An early study reporting the successful use of oral sildenafil in a child with severe pulmonary hypertension therefore attracted a lot of attention, not only within the medical community but also in the media ${ }^{104-106}$. Trials addressing the characterization of the acute effects of sildenafil on pulmonary and systemic haemodynamics in a larger number of patients with pulmonary arterial hypertension showed that sildenafil effectively reduced pulmonary vascular resistance in a dose-dependent manner ${ }^{107}$. Notably, the vasodilatory effects were restricted primarily to the pulmonary circulation, and were significantly stronger than the effects seen with inhaled NO. In combination with inhaled iloprost, augmentation of the pulmonary vasodilatory effect of each single agent was observed $^{107,108}$. Long-term treatment of patients with pulmonary arterial hypertension was investigated in a number of single-centre studies, all confirming the high efficacy and excellent tolerance of chronic oral sildenafil treatment ${ }^{109-111}$. In patients with deteriorating severe PAH despite ongoing prostanoid treatment, additional long-term administration of oral sildenafil improved exercise capacity and pulmonary haemodynamics ${ }^{112}$. The combination of prostanoids and sildenafil therefore has potential as a possible future treatment for pulmonary hypertension and numerous reports on the clinical use of sildenafil in pulmonary arterial hypertension in uncontrolled trials have been published to date $\mathrm{e}^{93,109,110,113-118}$.

Interestingly, sildenafil seems to also be effective for treating patients with pulmonary hypertension of origins other than primary pulmonary hypertension. In patients suffering from human immunodeficiency virus (HIV)related pulmonary hypertension, sildenafil was effective in reducing pulmonary vascular resistance, as it was in $\mathrm{PPH}{ }^{118,119}$. Recent data also suggest that long-term oral sildenafil treatment in patients with non-operable chronic thromboembolic pulmonary hypertension is beneficial ${ }^{120}$. The importance of this finding lies in the fact that there is currently little to offer these patients in the way of therapeutic options, with the exception of lung transplantation.

Pivotal trial and approval of sildenafil for the treatment of PAH (SUPER-1 study). The growing body of evidence from various studies between 1998-2001, which had already demonstrated the efficacy of sildenafil in the treatment of PAH, led to the design of a large, randomized, controlled, multinational trial to provide final proof of this new treatment concept, and to obtain legal approval for sildenafil as a new treatment for pulmonary arterial hypertension. The SUPER-1 (Sildenafil Use in Pulmonary HypERtension) study started in 2002 and included 278 patients with symptomatic pulmonary arterial hypertension who were treated either with placebo or sildenafil $(20,40$ or $80 \mathrm{mg})$ orally three times daily (TID) for 12 weeks. The primary endpoint in this trial - as in many previous trials with other medications similarly indicated - was the change from baseline to week 12 in the 6-minute walk test. Sildenafil, at all of the applied doses, improved exercise capacity (up to 50 metres (placebo-corrected value) in the $80 \mathrm{mg}$ TID group), functional class and haemodynamics, as compared with placebo-treated patients, and was very well tolerated ${ }^{121}$. Additionally, patients completing the double-blind phase were able to enter a long-term extension trial, which was conducted over a 2-year period with 80 $\mathrm{mg}$ sildenafil TID. The increase in the 6 -minute walk distance achieved after 3 months in the placebo-controlled phase was maintained even after a year of therapy, as were the improvements in functional class, which are both strongly indicative of the maintenance of the effect in spite of the severity of the disease.

Based on the very favourable mid- and long-term effects of this new oral treatment, sildenafil was approved by the FDA and the EMEA in 2005 for the treatment of patients suffering from $\mathrm{PAH}$. Both agencies decided to approve only the $20 \mathrm{mg}$ TID dose, as only a flat (nonsignificant) dose-effect relationship between 20-80 mg TID was observed regarding the primary endpoint of the study, the change in 6-minute walking distance over 12 weeks of treatment. In addition, analysis of sildenafil plasma levels in the SUPER-1 study showed no dose-effect relationship with the doses studied (Pfizer Chemical Research Group, unpublished data). There is evidence from some clinical and experimental settings that the duration of action of sildenafil might not be accurately reflected by plasma levels and the applied dosage ${ }^{122}$. It has been shown that the affinity of sildenafil for PDE5 is even increased after intracellular phosphorylation of the enzyme ${ }^{123}$. In addition, conformational changes to PDE5 and the slow dissociation rate of sildenafil from the enzyme could contribute to the flat dose-effect relationship ${ }^{124-127}$. One possible explanation is that sildenafil binding to the catalytic site of PDE5 could occur at higher affinity intracellularly than estimated 


\begin{tabular}{|c|c|c|}
\hline PDE family & Role(s) & Evidence* \\
\hline 1 & $\begin{array}{l}\text { Vascular smooth muscle } \\
\text { proliferation; } \mathrm{Ca}^{2+} \text { modulation } \\
\text { of olfaction }\end{array}$ & $\begin{array}{l}\text { Broad distribution, but highest levels in proliferating vascular smooth } \\
\text { muscle cells, testes, heart and neural tissues (for example, olfactory } \\
\text { epithelial cells). Binding and inactivation by } \mathrm{Ca}^{2+} / \text { calmodulin }\end{array}$ \\
\hline 2 & $\begin{array}{l}\text { Regulation of } \mathrm{Ca}^{2+} \text { channels, } \\
\text { olfaction, platelet aggregation } \\
\text { and aldosterone secretion }\end{array}$ & Broad distribution, but highest levels in brain and adrenal cortex ${ }^{197}$ \\
\hline 3 & $\begin{array}{l}\text { Cardiac contractility, insulin } \\
\text { secretion and lipolysis }\end{array}$ & $\begin{array}{l}\text { Broad distribution, but particular abundance in adipose tissue, liver, } \\
\text { cardiac muscle, vascular smooth muscle and platelets; inhibited by } \\
\text { drugs with cardiotonic, vasodilatory, thrombolytic, and antiplatelet } \\
\text { aggregation properties. Stimulated by insulin, leptin and insulin-like } \\
\text { growth factor }{ }^{198}\end{array}$ \\
\hline 4 & $\begin{array}{l}\text { Immunological and } \\
\text { inflammatory signalling } \\
\text { processes; smooth muscle } \\
\text { tone; depression }\end{array}$ & $\begin{array}{l}\text { Broad distribution, highest levels in neural and endocrine tissue. } \\
\text { Inflammatory cells thought to participate in the pathogenesis of } \\
\text { inflammatory diseases (such as asthma and chronic obstructive } \\
\text { pulmonary disease) preferentially express PDE4 }\end{array}$ \\
\hline 5 & $\begin{array}{l}\text { Penile erection; smooth muscle } \\
\text { tone of vasculature, airways } \\
\text { and gastrointestinal tract }\end{array}$ & $\begin{array}{l}\text { Abundant distribution in smooth muscle. The PDE5-specific inhibitor } \\
\text { sildenafil has clinical efficacy for the treatment of erectile dysfunction }\end{array}$ \\
\hline 6 & Vision & $\begin{array}{l}\text { Distribution in rod and cone photoreceptor cells. Some visual defects } \\
\text { are related to PDE6 mutations }\end{array}$ \\
\hline 7 & $\begin{array}{l}\text { T-lymphocyte activation and } \\
\text { proliferation; skeletal muscle } \\
\text { metabolism }\end{array}$ & $\begin{array}{l}\text { Distribution is predominantly in T lymphocytes (PDE7A1). PDE7 mRNA } \\
\text { is abundant in skeletal muscle tissue, T lymphocytes and B lymphocytes, } \\
\text { but protein and activity are readily measurable only in T lymphocytes }\end{array}$ \\
\hline 8 & T-cell activation & $\begin{array}{l}\text { PDE8A mRNA is widely expressed (highest in testis). PDE8B is unique } \\
\text { to the thyroid gland }{ }^{199}\end{array}$ \\
\hline 9 & $\begin{array}{l}\text { Possibly maintains basal } \\
\text { intracellular cGMP levels or } \\
\text { natriuresis and vascular tone }\end{array}$ & $\begin{array}{l}\text { mRNA is widely expressed, particularly in spleen, intestine, kidney, } \\
\text { heart and brain }\end{array}$ \\
\hline 10 & Unknown & Human PDE10 is widely distributed \\
\hline 11 & $\begin{array}{l}\text { Sperm capacitation; other } \\
\text { functions unknown }\end{array}$ & $\begin{array}{l}\text { mRNA occurs at highest levels in skeletal muscle, prostate, kidney, liver, } \\
\text { pituitary and salivary glands, and testis. Protein is localized to vascular } \\
\text { smooth muscle cells, cardiac myocytes, corpus cavernosum of the penis, } \\
\text { prostate and skeletal muscle }\end{array}$ \\
\hline
\end{tabular}

previously, which might retard clearance of the inhibitor from the cells (G. Butrous, personal communication). On the other hand, however, in the SUPER-1 trial there were clear trends in some secondary endpoints (some showed statistically significant differences between the three applied doses) indicating that, for a subgroup of patients, higher doses might be more efficacious than the approved $20 \mathrm{mg}$ TID dosage. Moreover, in the majority of preceding short- and long-term studies, daily doses of 100-300 mg were investigated and reported to be efficacious and well tolerated ${ }^{107-109,111,128}$. Future studies are therefore warranted that address the long-term efficacy of $20 \mathrm{mg}$ TID or even lower doses of sildenafil for the treatment of $\mathrm{PAH}$.

\section{Future indications for PDE5 inhibitors} Raynaud's phenomenon and digital ulcers in collagen vascular diseases. Patients with pulmonary arterial hypertension often complain about intermittent, temperature-dependent peripheral vasospasms resulting in perfusion deficiencies in their fingers and toes (socalled Raynaud's phenomenon) even in the absence of a proven collagen vascular disease $\mathrm{e}^{129-131}$. When treated with vasodilators, these symptoms can improve in parallel with, but also independent of, improvements in pulmonary haemodynamics. Raynaud's phenomenon and digital ulcers are of an even higher prevalence, and are clinically more important, in patients with systemic sclerosis, CREST syndrome (which comprises calcinosis cutis, Raynaud's phenomenon, oesophageal dysmotility, sclerodactyly and teleangiectasis), and systemic lupus erythematosus ${ }^{132}$. Treatment currently includes the application of calcium-channel blockers, infused prostanoids and alpha-2 blockade ${ }^{133-135}$. However, the clinical efficacy of these therapies is often modest at best. A growing number of uncontrolled trials indicated that the efficacy of sildenafil for the treatment of digital ulceration and Raynaud's phenomenon in patients with scleroderma with or without pulmonary hypertension ${ }^{136-139}$ warranted attention. In an initial randomized controlled trial, Fries et al. investigated the effects of sildenafil ( $50 \mathrm{mg}$ given twice daily) on the symptoms and capillary perfusion in patients with Raynaud's phenomenon ${ }^{140}$. Most notably, only patients previously treated with other vasodilators that showed insufficient improvement were included in this trial. In contrast to the effects of placebo, chronic sildenafil treatment for 4 weeks reduced the mean frequency and duration of Raynaud attacks, and lowered the 
Matching

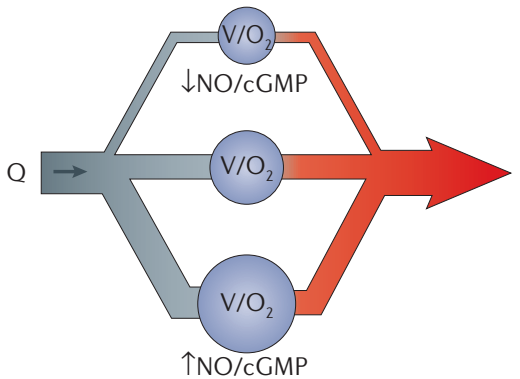

Mismatch

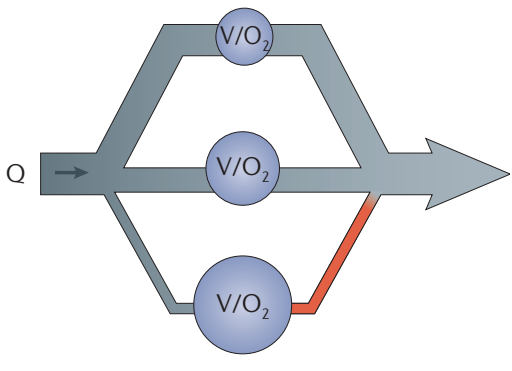

Figure 5 | Adaptation of blood flow to ventilation in the pulmonary circulation. Blood flow (Q) in the pulmonary circulation must, ideally, be directed to well-ventilated areas (symbolized by big $\mathrm{V}$ (ventilation) and $\mathrm{O}_{2}$ (oxygenation) in the largest alveolus (blue circle at bottom of figure)) to ensure optimized gas exchange ('matching'), whereas only a small amount of blood should flow through areas of minor or no ventilation (midsize and small alveolus, respectively) (left panel). Lung vessel dilatation is mainly regulated by the compartmentalized production of nitric oxide (NO) and subsequent intracellular cGMP formation, where alveolar distension and oxygenation represent the most potent stimuli for this local NO release. Similarly, less NO/cGMP is produced in non-ventilated areas of the lung, resulting in hypoxic vasoconstriction (the so called von Euler-Liljestrand mechanism). During application of non-selective vasodilators and/or under disease conditions (for example, chronic obstructive lung disease, lung fibrosis, sepsis or acute respiratory distress syndrome), vasodilatation is induced in poorly or non-ventilated areas of the lung resulting in venous admixture and worsening of gas-exchange ('mismatch', right panel). There is strong evidence that oral sildenafil preferentially dilates vessels in well-ventilated areas of the lung, thereby both reducing overall vascular resistance and improving overall oxygenation ('re-matching' drug) ) $^{143,144}$.

Exercise tolerance Ability to perform physical strain until limited by occurrence of peripheral (muscular) exhaustion, shortness of breath and/or insufficient blood supply to the myocardium (due, for example, to coronary heart disease). mean Raynaud's condition score significantly. Moreover, capillary blood flow velocity increased in each individual patient, and the mean capillary flow velocity of all patients more than quadrupled after treatment with sildenafil ${ }^{140}$. Interestingly, although sildenafil had clear effects in the affected vascular areas, significant reductions of the systemic blood pressure were not reported in any of the aforementioned studies. These findings fit in with the notion of the selectivity of sildenafil for certain vascular beds (such as the pulmonary circulation and corpus cavernosum) and indicates that PDE5 might be differentially expressed in the remodelled vasculature of digital ulcers as opposed to the non-affected regions of the systemic circulation ${ }^{141}$. Taken together, there is a good rationale to further develop sildenafil as new treatment for Raynaud's phenomenon and digital ulcerations.

Pulmonary hypertension associated with ventilatory disorders. When pulmonary hypertension is associated with interstitial lung disease, systemic administration of vasodilators increases the blood flow to low- or non-ventilated areas of the lung by interfering with the physiological hypoxic vasoconstrictor mechanism. This worsens preexistent ventilation(V)/perfusion( $(\mathrm{Q})$ mismatch and shunt flow ${ }^{142}$. The decrease in arterial oxygenation and wasting of the small ventilatory reserve of these patients are important negative consequences of this effect. Oral sildenafil, however, caused pulmonary vasodilatation in patients with lung fibrosis and pulmonary hypertension, with an overall vasodilatory potency corresponding to that of intravenous prostacyclin. In contrast to the infused prostanoid, selectivity for well-ventilated lung areas was demonstrated for sildenafil, resulting in an improvement, rather than deterioration, of gas exchange ${ }^{143}$. Pulmonary hypertension impairs right ventricular performance because it increases right-heart afterload. However, it is still unclear to what extent exercise tolerance is limited by this mechanism. In a recent investigation, this issue was addressed under conditions of acute hypoxia at sea level, and prolonged hypoxia at the altitude of Mount Everest Base Camp ${ }^{144}$. These investigations were performed in healthy volunteers to exclude other confounding factors that might have added to the limitation of exercise tolerance in patients suffering from chronic hypoxia (such as muscle wasting or chronic immobilization). In essence, acute and prolonged hypoxia induced significant pulmonary hypertension in the study subjects. As expected, exercise tolerance was dramatically reduced as a consequence of severe hypoxaemia and significant pulmonary hypertension. Sildenafil significantly reduced pulmonary hypertension under resting conditions, as well as during exercise. The most interesting finding of this study was that the reversal of pulmonary hypertension resulted in an immediate improvement of exercise tolerance, irrespective of improvements in oxygenation. Further studies investigating the effects of acute and chronic sildenafil administration in hypoxic pulmonary hypertension confirmed the anti-pulmonary hypertensive potential, and the beneficial effects of sildenafil on exercise performance, under these conditions ${ }^{145,146}$. The results of these studies stimulated further investigations that addressed the therapeutic potential of this drug in patients suffering from chronic hypoxic pulmonary hypertension as it occurs in various chronic diseases (such as chronic obstructive pulmonary disease (COPD), interstitial lung disease and obstructive sleep apnoea $)^{147-150}$. In fact, very recent work supports the possibility of effective treatment of pulmonary hypertension in patients suffering from advanced COPD ${ }^{151}$. Based on the significant impact of COPD on public health, studies in this field are warranted.

Heart failure. Chronic heart load leads to ventricular hypertrophy as an initial process of adaptation and can ultimately result in ventricular dilatation and failure if not treated chronically ${ }^{152}$. Although cardiac hypertrophy applies both to disorders that lead to left ventricular loading as well as those that lead to right ventricular loading, there are important differences with respect to the reversibility of muscular hypertrophy of both ventricles. Although the right ventricle - even at advanced stages of dilatation and decompensation - can return to almost normal structure and function once the load is effectively reduced, left ventricular hypertrophy is only partly reversible once a certain degree of hypertrophy has been exceeded ${ }^{153,154}$. In chronic pulmonary hypertension, right ventricular dysfunction is the ultimate cause of death over the course of the disease; however, effective reduction of the pulmonary vascular resistance - after lung transplantation, for example - might reverse right ventricular hypertrophy ${ }^{155}$. Wilkins et al. have elegantly shown that effective treatment of pulmonary arterial 


\section{Box 1 | Further insights into the mechanism of action of sildenafil}

An interesting further insight into the mode of action of sildenafil comes from several preclinical investigations, including a recent publication by Musicki et al. ${ }^{190}$, which investigated the effects of long-term treatment of sildenafil in young and aged rats. In aged rats, but not in their young counterparts, sildenafil prolonged erection and increased the protein expression of phosphorylated endothelial nitric oxide synthase (eNOS) and phosphorylated Akt. Therefore the description of the mode of action of sildenafil in erectile dysfunction, and possibly also in pulmonary vascular diseases, can be further elaborated. It can be proposed that the initial increase in $\mathrm{NO}$ levels - due to neurogenic stimulation or a result of alveolar distension, for example - is followed by subsequent maintenance of vasodilatation by increased endothelial generation of $\mathrm{NO}$ via activated eNOS. It can also be speculated that the resulting increase in blood flow, and consequently shear stress, across the vascular endothelial cell surface activates phosphatidylinositol 3-kinase (PI3K)/Akt, which phosphorylate and thereby further activate eNOS. The activated eNOS can then lead to a sustained further release of NO, which acts to maintain the smooth muscle relaxation, vascular engorgement and increased blood flow (see figure). As sildenafil is being explored for other potential indications, and provided there is a dual effect of chronic administration on activation of eNOS and inhibition of the phosphodiesterase type 5 (PDE5), the therapeutic potential for various diseases involving vascular pathology might therefore be greater than originally envisaged.

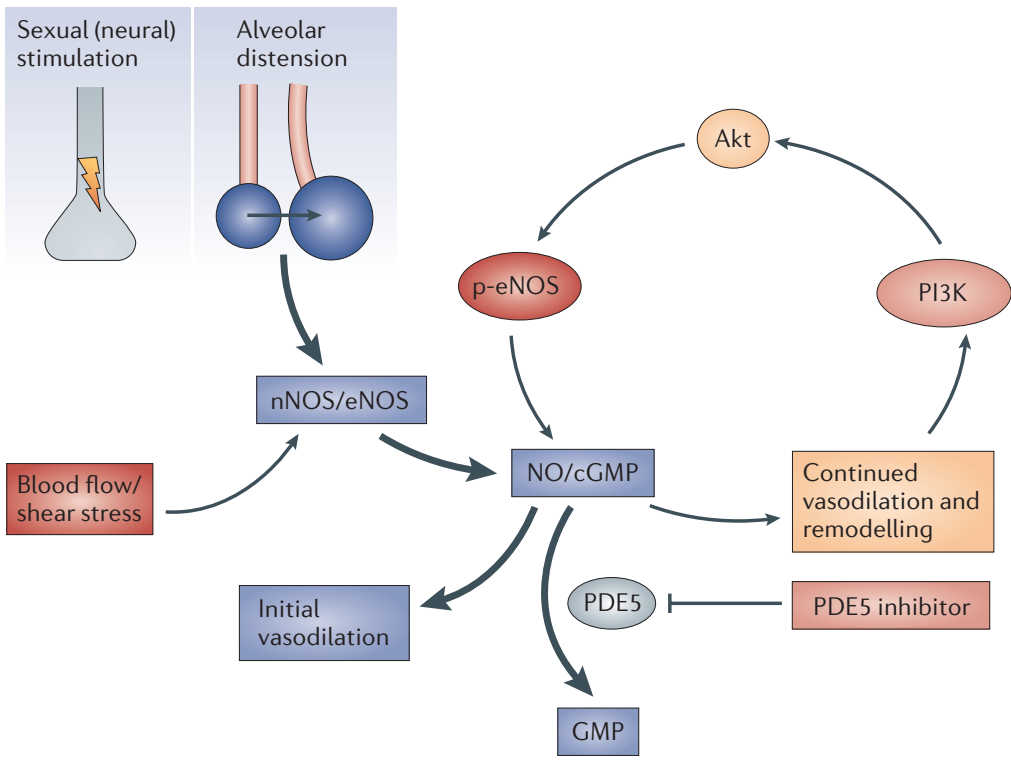

hypertension with sildenafil not only improved functional capacity, but also reduced right ventricular mass in these patients, as assessed by magnetic resonance imaging ${ }^{156}$. This was even more interesting because the effects of sildenafil on right ventricular remodelling were significantly more prominent than those seen with the non-selective endothelin receptor antagonist bosentan. To date, reduction of right ventricular hypertrophy in patients with chronic pulmonary hypertension has been attributed exclusively to treatment-related reductions in right ventricular load ${ }^{157-160}$. However, the observations of Wilkins and colleagues must now be viewed in a different light, because recent studies have proposed a direct antihypertrophic effect of sildenafil on cardiomyocytes ${ }^{161}$. In their intriguing study, Takimoto and colleagues conclusively showed that sildenafil reduced ventricular hypertrophy and improved myocardial function in a mouse model of chronic left ventricular pressure load (induced by transaortic constriction) in a protein kinase G1-dependent manner. Furthermore,
cGMP levels were shown to be inversely correlated with cardiac hypertrophy in an isoproterenol-induced cardiac hypertrophy model in rats ${ }^{162}$.

However, the potential usefulness of sildenafil in chronic heart failure might result from a variety of actions in addition to an effect on ventricular hypertrophy. A variety of investigations have indicated that sildenafil can be cautiously administered to selected patients with left heart failure ${ }^{163-172}$. Endothelial function (the capacity of arterioles to enable increases in regional blood flow in response to appropriate stimuli such as ischaemia) is severely limited in chronic congestive heart failure. In an elegant study Katz et al..$^{42}$ showed that sildenafil could improve endothelial function in such patients. Further studies investigating the long-term effects of PDE5 inhibitors in patients with these diseases would therefore be logical. Also, by virtue of its effect on vasodilatation, arterial stiffness and wave reflection, sildenafil has been shown to reduce aortic pressure and the augmentation index, and could therefore have a role in the management of systemic hypertension ${ }^{41}$.

Cerebral circulation. Various studies have provided compelling evidence for a functional role of the NO-cGMP pathway in the brain ${ }^{173,174}$. Inhibition of hippocampal NOS resulted in a state-dependent impairment in object recognition ${ }^{175}$. As no direct influence of PDE5 inhibitors on the overall cerebral blood flow was found ${ }^{173,176,177}$, the functional changes described in response to these agents were attributed to neuronal alterations ${ }^{178}$. Static flow-measures might, however, not be the appropriate parameter to characterize changes in microcirculatory adaptation to demand, where this regulation is mediated via neurovascular coupling in a fast and fine-tuned manner ${ }^{179-181}$. Concerning the cerebral vasculature, numerous studies have addressed the distribution of regional brain perfusion in health and disease states ${ }^{176,182-184}$. Investigations addressing the cerebral effects of sildenafil showed no changes in overall cerebral blood flow ${ }^{173,175,177}$ after administration of this agent. On the other hand, despite the absence of changes in overall cerebral blood flow, an effect of the PDE5 system on cognitive function ${ }^{185}$, repair mechanisms after stroke and expression profiles of second messenger levels in distinct brain areas have been proposed ${ }^{45,186,187}$. This discrepancy might well be reconciled by a recent finding suggesting that sildenafil significantly improves neurovascular coupling while leaving overall cerebral blood flow unchanged ${ }^{188}$. Furthermore, this finding is in line with previous observations that the initial blood flow response to cortical activity is mainly governed by stimulation of the NO system ${ }^{187}$. It has also been proposed that there might be therapeutic potential for sildenafil in cerebral ischaemic disorders, because cGMP levels were shown to be involved in the repair of ischaemic brain tissue and sildenafil reduced the size of the infarction area in an experimental rodent model ${ }^{45}$. Interestingly, the same group provided evidence that sildenafil significantly increased cGMP levels and induced neurogenesis in a model of neuronal growth ${ }^{189}$. The study also showed that sildenafil significantly upregulated the phosphorylation of Akt in neurospheres. This effect was associated 


\begin{tabular}{|c|c|c|c|c|c|c|c|c|c|c|c|c|}
\hline \multirow[t]{2}{*}{ Drug } & \multicolumn{12}{|c|}{ Geometric mean IC ${ }_{50}$ values $(\mu \mathrm{M})$ [fold selectivity versus PDE5 in parentheses] } \\
\hline & PDE1 & PDE2 & PDE3 & PDE4 & PDE5 & $\begin{array}{l}\text { PDE6 } \\
\text { (rod) }\end{array}$ & $\begin{array}{l}\text { PDE6 } \\
\text { (cone) }\end{array}$ & PDE7A & PDE8A & PDE9A & PDE10A & PDE11A \\
\hline Sildenafil & $\begin{array}{l}0.281 \\
{[80]}\end{array}$ & $\begin{array}{l}>30 \\
{[>8,570]}\end{array}$ & $\begin{array}{l}16.2 \\
{[4,630]}\end{array}$ & $\begin{array}{l}7.68 \\
{[2,190]}\end{array}$ & 0.00350 & $\begin{array}{l}0.037 \\
{[11]}\end{array}$ & $\begin{array}{l}0.034 \\
{[10]}\end{array}$ & $\begin{array}{l}21.3 \\
{[6,090]}\end{array}$ & $\begin{array}{l}29.8 \\
{[8,510]}\end{array}$ & $2.61[750]$ & $\begin{array}{l}9.80 \\
{[2,800]}\end{array}$ & $\begin{array}{l}2.73 \\
{[780]}\end{array}$ \\
\hline Tadalafil & $\begin{array}{l}>30 \\
{[>4,450]}\end{array}$ & $\begin{array}{l}>100 \\
{[>14,800]}\end{array}$ & $\begin{array}{l}>100 \\
{[>14,800]}\end{array}$ & $\begin{array}{l}>100 \\
{[>14,800]}\end{array}$ & 0.00674 & $\begin{array}{l}1.26 \\
{[187]}\end{array}$ & $\begin{array}{l}1.30 \\
{[193]}\end{array}$ & $\begin{array}{l}>100 \\
{[>14,800]}\end{array}$ & $\begin{array}{l}>100 \\
{[>14,800]}\end{array}$ & $\begin{array}{l}>100 \\
{[>14,800]}\end{array}$ & $\begin{array}{l}>100 \\
{[>14,800]}\end{array}$ & $0.037[5]$ \\
\hline Vardenafil & $\begin{array}{l}0.070 \\
{[500]}\end{array}$ & $\begin{array}{l}6.20 \\
{[44,290]}\end{array}$ & $\begin{array}{l}>1.0 \\
{[>7,140]}\end{array}$ & $\begin{array}{l}6.10 \\
{[43,570]}\end{array}$ & 0.00014 & $\begin{array}{l}0.0035 \\
{[25]}\end{array}$ & $\begin{array}{l}0.0006 \\
{[4]}\end{array}$ & $\begin{array}{l}>30 \\
{[>214,000]}\end{array}$ & $\begin{array}{l}>30 \\
{[>214,000]}\end{array}$ & $\begin{array}{l}0.581 \\
{[4,150]}\end{array}$ & $\begin{array}{l}3.0 \\
{[21,200]}\end{array}$ & $\begin{array}{l}0.162 \\
{[1,160]}\end{array}$ \\
\hline
\end{tabular}

$\mathrm{IC}_{50}$ values were determined using either native enzyme purified from human tissue (PDE1, heart; PDEs 2, 3 and 5, corpus cavernosum; PDE4, skeletal muscle; PDE6, retina) or using recombinant human enzymes expressed in Sf9 cells (PDEs 7-11) and purified by anion-exchange chromatography. Adapted from $\mathrm{REF}^{2}$. $9 . \mathrm{IC}_{50}$, drug concentration necessary to inhibit $50 \%$ of enzyme activity; PDE, phosphodiesterase.

with an increase in the phosphorylation of glycogen synthase kinase 3 (GSK3), a downstream target of Akt. Co-incubation of neurospheres with sildenafil and LY 294002, a pharmacological inhibitor of phosphatidylinositol 3-kinase (PI3K)/Akt, abolished sildenafilinduced phosphorylation of Akt and GSK3, suggesting that sildenafil enhanced neurogenesis through activation of the PI3K/Akt/GSK3 pathway.

\section{Conclusion}

Sildenafil started clinical development as an agent for the treatment of hypertension and angina, and subsequently evolved into a revolutionary new oral treatment for erectile dysfunction. Sildenafil was then further developed to become a much-needed new oral treatment for pulmonary arterial hypertension, and has also been shown to be effective in treating severe Raynaud's phenomenon associated with systemic sclerosis and digital ulceration. Later investigative studies have suggested that sildenafil also has promise in the treatment of respiratory disorders with ventilation/perfusion mismatch, congestive cardiac failure, hypertension and even stroke. Moreover, many years after the original indication was abandoned, single-dose sildenafil was shown to prolong exercise time in men with angina. Although these findings might seem to be quite disparate and unrelated, all of the disorders described above are in fact characterized by regional deficiencies in blood supply. The successful application of a PDE5 inhibitor (as opposed to non-selective vasodilators) to treat these conditions can be understood in terms of the capacity of sildenafil to reverse endothelial dysfunction, and to selectively improve regional blood flow in areas of greatest need. Further applications of PDE5 inhibitors may arise from new insights into the mode of action of chronic sildenafil administration (BOX 1) ${ }^{190}$. Many patients with erectile dysfunction and pulmonary arterial hypertension are now benefiting from advances in our understanding of vascular biology and pathophysiology, and the advent of selective inhibitors of PDE5 (TABLE 3). It is hoped that the clinical potential of this mechanism to treat the other serious medical conditions described above (and others such as pre-eclampsia and certain forms of intrauterine growth retardation) will soon be realized, so that many more patients can benefit from these amazing breakthroughs in science, technology and medicine.
1. Marsh, N. \& Marsh, A. A short history of nitroglycerine and nitric oxide in pharmacology and physiology. Clin. Exp. Pharmacol. Physiol. 27, 313319 (2000).

2. Moncada, S., Palmer, R. M. \& Higgs, E. A. Nitric oxide: physiology, pathophysiology, and pharmacology. Pharmacol. Rev. 43, 109-142 (1991).

An excellent review of the physiology and pathophysiology of nitric oxide and the pharmacological implications of this important molecule.

3. Pfeifer, A. et al. Structure and function of cGMPdependent protein kinases. Rev. Physiol. Biochem. Pharmacol. 135, 105-149 (1999).

4. Lucas, K. A. et al. Guanylyl cyclases and signaling by cyclic GMP. Pharmacol. Rev. 52, 375-414 (2000). Parker, J. D. \& Parker, J. O. Nitrate therapy for stable angina pectoris. N. Engl. J. Med. 338, 520-531 (1998).

6. Corbin, J. D. \& Francis, S. H. Cyclic GMP phosphodiesterase-5: target of sildenafil. J. Biol. Chem. 274, 13729-13732 (1999).

An informative review about sildenafil and its target, PDE5, from two scientists that contributed significantly to this research area.

7. Terrett, N. K., Bell, A. S., Brown, D. \& Ellis, P. Sildenafil (VIAGRA(TM)), a potent and selective inhibitor of type 5 cGMP phosphodiesterase with utility for the treatment of male erectile dysfunction. Bioorg. Med. Chem. Lett. 6, 1819-1824 (1996).
8. Wallis, R. M., Corbin, J. D., Francis, S. H. \& Ellis, P. Tissue distribution of phosphodiesterase families and the effects of sildenafil on tissue cyclic nucleotides, platelet function, and the contractile responses of trabeculae carneae and aortic rings in vitro. Am. J. Cardiol. 83, 3C-12C (1999).

9. Campbell, S. F. Science, art and drug discovery: a personal perspective. Clin. Sci. (Lond) 99, 255-260 (2000).

10. Walker, D. K. et al. Pharmacokinetics and metabolism of sildenafil in mouse, rat, rabbit, dog and man. Xenobiotica 29, 297-310 (1999).

11. Ballard, S. A. et al. Effects of sildenafil on the relaxation of human corpus cavernosum tissue in vitro and on the activities of cyclic nucleotide phosphodiesterase isozymes. J. Urol. 159, $2164-$ 2171 (1998).

12. Webb, D. J., Freestone, S., Allen, M. J. \& Muirhead, G $J$ Sildenafil citrate and blood-pressure-lowering drugs: results of drug interaction studies with an organic nitrate and a calcium antagonist. Am. J. Cardiol. 83, 21C-28C (1999).

13. Ignarro, L. J. et al. Nitric oxide and cyclic GMP formation upon electrical field stimulation cause relaxation of corpus cavernosum smooth muscle. Biochem. Biophys. Res. Commun. 170, 843-850 (1990).

14. Bush, P. A., Aronson, W. J., Buga, G. M., Rajfer, J. \& Ignarro, L. J. Nitric oxide is a potent relaxant of human and rabbit corpus cavernosum. J. Urol. 147, 1650-1655 (1992)
15. Azadzoi, K. M. et al. Endothelium-derived nitric oxide and cyclooxygenase products modulate corpus cavernosum smooth muscle tone. J. Urol. 147, 220225 (1992).

16. Boolell, M. et al. Sildenafil: an orally active type 5 cyclic GMP-specific phosphodiesterase inhibitor for the treatment of penile erectile dysfunction. Int. J. Impot. Res. 8, 47-52 (1996).

First report from a Pfizer research group indicating that sildenafil holds promise as a new effective oral treatment for penile erectile dysfunction.

17. Rosen, R. C., Cappelleri, J. C. \& Gendrano, N., III The International Index of Erectile Function (IIEF): a stateof-the-science review. Int. J. Impot. Res. 14, 226-244 (2002).

Important review of the International Index of Erectile Function (IIEF), the current 'gold standard' measure for efficacy assessment in clinical trials of erectile dysfunction.

18. Eardley, I., Ellis, P., Boolell, M. \& Wulff, M. Onset and duration of action of sildenafil for the treatment of erectile dysfunction. Br. J. Clin. Pharmacol. 53 (Suppl. 1), 61S-65S (2002).

19. Goldstein, I. et al. Oral sildenafil in the treatment of erectile dysfunction. Sildenafil Study Group. N. Engl. J. Med. 338, 1397-1404 (1998).

First publication of the results of two sequential double-blind studies proving the efficacy and safety of sildenafil, administered as needed in men with erectile dysfunction. 
20. Montorsi, F. et al. Efficacy and safety of fixed-dose oral sildenafil in the treatment of erectile dysfunction of various etiologies. Urology 53, 1011-1018 (1999).

21. Dinsmore, W. W. et al. Sildenafil citrate (Viagra) in erectile dysfunction: near normalization in men with broad-spectrum erectile dysfunction compared with age-matched healthy control subjects. Urology 53 , 800-805 (1999)

22. Stuckey, B. G. et al. Sildenafil citrate for treatment of erectile dysfunction in men with type 1 diabetes: results of a randomized controlled trial. Diabetes Care 26, 279-284 (2003)

23. Rendell, M. S., Rajfer, J., Wicker, P. A. \& Smith, M. D. Sildenafil for treatment of erectile dysfunction in men with diabetes: a randomized controlled trial. Sildenafil Diabetes Study Group. JAMA 281, 421-426 (1999).

24. Olsson, A. M. \& Persson, C. A. Efficacy and safety of sildenafil citrate for the treatment of erectile dysfunction in men with cardiovascular disease. Int. J. Clin. Pract. 55, 171-176 (2001).

25. Fowler, C. J. et al. A double blind, randomised study of sildenafil citrate for erectile dysfunction in men with multiple sclerosis. J. Neurol. Neurosurg. Psychiatry 76, 700-705 (2005)

26. Derry, F. A. et al. Efficacy and safety of oral sildenafi (Viagra) in men with erectile dysfunction caused by spinal cord injury. Neurology 51, 1629-1633 (1998).

27. Ogura, K. et al. Role of sildenafil citrate in treatment of erectile dysfunction after radical retropubic prostatectomy. Int. J. Urol. 11, 159-163 (2004).

28. Morales, A., Gingell, C., Collins, M., Wicker, P. A. \& Osterloh, I. H. Clinical safety of oral sildenafil citrate (VIAGRA) in the treatment of erectile dysfunction. Int. J. Impot. Res. 10, 69-73 (1998).

Very informative data analysis on safety and tolerability of sildenafil in the treatment of erectile dysfunction from a series of double-blind, placebocontrolled studies and from ten open-label extension studies.

29. Gbekor, E., Bethell, S., Fawcett, L., Mount, N. \& Phillips, S. Phosphodiesterase 5 inhibitor profile against all human phosphodiesterase families: Implications for use as pharmacological tools. J. Urol. 167 (Suppl.), S246 (2002).

30. Laties, A. \& Zrenner, E. Viagra (sildenafil citrate) and ophthalmology. Prog. Retin. Eye Res. 21, 485-506 (2002).

31. Marmor, M. F. \& Kessler, R. Sildenafil (Viagra) and ophthalmology. Surv. Ophthalmol. 44, 153-162 (1999).

32. Abbott, D. et al. Preclinical safety profile of sildenafil. Int. J. Impot. Res. 16, 498-504 (2004).

33. Herrmann, H. C., Chang, G., Klugherz, B. D. \& Mahoney, P. D. Hemodynamic effects of sildenafil in men with severe coronary artery disease. N. Engl. J. Med. 342, 1622-1626 (2000). First systematic clinical trial proving that sildenafi had no adverse cardiovascular effects in men with severe coronary artery disease.

34. Arruda-Olson, A. M., Mahoney, D. W., Nehra, A. Leckel, M. \& Pellikka, P. A. Cardiovascular effects of sildenafil during exercise in men with known or probable coronary artery disease: a randomized crossover trial. JAMA 287, 719-725 (2002).

35. DeBusk, R. F. et al. Efficacy and safety of sildenafil citrate in men with erectile dysfunction and stable coronary artery disease. Am. J. Cardiol. 93, 147-153 (2004).

36. Wysowski, D. K., Farinas, E. \& Swartz, L. Comparison of reported and expected deaths in sildenafil (Viagra) users. Am. J. Cardiol. 89, 1331-1334 (2002).

37. Boshier, A., Wilton, L. V. \& Shakir, S. A. Evaluation of the safety of sildenafil for male erectile dysfunction: experience gained in general practice use in England in 1999. BJU Int. 93, 796-801 (2004).

38. Fox, K. M. et al. Sildenafil citrate does not reduce exercise tolerance in men with erectile dysfunction and chronic stable angina. Eur. Heart J. 24, 2206-2212 (2003).

39. Halcox, J. P. et al. The effect of sildenafil on human vascular function, platelet activation, and myocardial ischemia. J. Am. Coll. Cardiol. 40, 1232-1240 (2002).

40. Bocchi, E. A. et al. Sildenafil effects on exercise neurohormonal activation, and erectile dysfunction in congestive heart failure: a double-blind, placebocontrolled, randomized study followed by a prospective treatment for erectile dysfunction. Circulation 106, 1097-1103 (2002).
41. Mahmud, A., Hennessy, M. \& Feely, J. Effect of sildenafil on blood pressure and arterial wave reflection in treated hypertensive men. J. Hum Hypertens. 15, 707-713 (2001).

42. Katz, S. D. et al. Acute type 5 phosphodiesterase inhibition with sildenafil enhances flow-mediated vasodilation in patients with chronic heart failure. $J$. Am. Coll. Cardiol. 36, 845-851 (2000).

43. Desouza, C., Parulkar, A., Lumpkin, D., Akers, D. \& Fonseca, V. A. Acute and prolonged effects of sildenafi on brachial artery flow-mediated dilatation in type 2 diabetes. Diabetes Care 25, 1336-1339 (2002).

44. Ockaili, R., Salloum, F., Hawkins, J. \& Kukreja, R. C. Sildenafil (Viagra) induces powerful cardioprotective effect via opening of mitochondrial K(ATP) channels in rabbits. Am. J. Physiol. Heart Circ. Physiol. 283 H1263-H1269 (2002).

45. Zhang, R. et al. Sildenafil (Viagra) induces neurogenesis and promotes functional recovery after stroke in rats. Stroke 33, 2675-2680 (2002).

46. Egan, R. \& Pomeranz, H. Sildenafil (Viagra) associated anterior ischemic optic neuropathy. Arch. Ophthalmol. 118, 291-292 (2000)

47. Cunningham, A. V. \& Smith, K. H. Anterior ischemic optic neuropathy associated with viagra. $J$. Neuroophthalmol. 21, 22-25 (2001).

48. Pomeranz, H. D., Smith, K. H., Hart, W. M. Jr. \& Egan, R. A. Sildenafil-associated nonarteritic anterior ischemic optic neuropathy. Ophthalmology 109 584-587 (2002).

49. Pomeranz, H. D. \& Bhavsar, A. R. Nonarteritic ischemic optic neuropathy developing soon after use of sildenafil (viagra): a report of seven new cases. $J$. Neuroophthalmol. 25, 9-13 (2005).

50. Gorkin, L., Hvidsten, K., Sobel, R. E. \& Siegel, R Sildenafil citrate use and the incidence of nonarteritic anterior ischemic optic neuropathy. Int. J. Clin. Pract. 60, 500-503 (2006).

51. Hattenhauer, M. G., Leavitt, J. A., Hodge, D. O., Grill, R. \& Gray, D. T. Incidence of nonarteritic anterio ischemic optic neuropathy. Am. J. Ophthalmol. 123 103-107 (1997).

52. Johnson, L. N. \& Arnold, A. C. Incidence of nonarteritic and arteritic anterior ischemic optic neuropathy. Population-based study in the state of Missouri and Los Angeles County, California. J. Neuroophthalmol. 14, 38-44 (1994).

53. Fraunfelder, F. W., Pomeranz, H. D. \& Egan, R. A. Nonarteritic anterior ischemic optic neuropathy and sildenafil. Arch. Ophthalmol. 124, 733-734 (2006).

54. Jackson, G., Gillies, H. \& Osterloh, I. Past, present, and future: a 7-year update of Viagra (sildenafil citrate). Int. J. Clin. Pract. 59, 680-691 (2005).

55. Sanchez, L. S. et al. Cyclic-GMP-binding, cyclic-GMPspecific phosphodiesterase (PDE5) gene expression is regulated during rat pulmonary development. Pediatr. Res. 43, 163-168 (1998).

56. Ziegler, J. W. et al. Effects of dipyridamole and inhaled nitric oxide in pediatric patients with pulmonary hypertension. Am. J. Respir. Crit. Care Med. 158 1388-1395 (1998)

57. Ichinose, F., Adrie, C., Hurford, W. E., Bloch, K. D. \& Zapol, W. M. Selective pulmonary vasodilation induced by aerosolized zaprinast. Anesthesiology 88 410-416 (1998).

58. Ichinose, F., Adrie, C., Hurford, W. E. \& Zapol, W. M. Prolonged pulmonary vasodilator action of inhaled nitric oxide by Zaprinast in awake lambs. J. Appl. Physiol. 78, 1288-1295 (1995).

59. Nagamine, J., Hill, L. L. \& Pearl, R. G. Combined therapy with zaprinast and inhaled nitric oxide abolishes hypoxic pulmonary hypertension. Crit. Care Med. 28, 2420-2424 (2000).

60. Thusu, K. G., Morin, F. C., III, Russell, J. A. \& Steinhorn, R. H. The cGMP phosphodiesterase inhibitor zaprinast enhances the effect of nitric oxide. Am. J. Respir. Crit. Care Med. 152, 1605-1610 (1995).

61 Humbert, M et al. Cellular and molecular pathobiology of pulmonary arterial hypertension. $J$. Am. Coll. Cardiol. 43, 13S-24S (2004).

62. Simonneau, G. et al. Clinical classification of pulmonary hypertension. J. Am. Coll. Cardiol. 43, 5S-12S (2004).

63. Cogan, J. D. et al. Gross BMPR2 gene rearrangements constitute a new cause for primary pulmonary hypertension. Genet. Med. 7, 169-174 (2005)

64. Lane, K. B. et al. Heterozygous germline mutations in BMPR2, encoding a TGF- $\beta$ receptor, cause familial primary pulmonary hypertension. The International PPH Consortium. Nature Genet. 26, 81-84 (2000).
65. Machado, R. D. et al. BMPR2 haploinsufficiency as the inherited molecular mechanism for primary pulmonary hypertension. Am. J. Hum. Genet. 68, 92 102 (2001).

66. Galie, N., Manes, A. \& Branzi, A. Emerging medica therapies for pulmonary arterial hypertension. Prog. Cardiovasc. Dis. 45, 213-224 (2002).

67. Barst, R. J. et al. A comparison of continuous intravenous epoprostenol (prostacyclin) with conventional therapy for primary pulmonary hypertension. The Primary Pulmonary Hypertension Study Group. N. Engl. J. Med. 334, 296-302 (1996)

68. Badesch, D. B. et al. Continuous intravenous epoprostenol for pulmonary hypertension due to the scleroderma spectrum of disease. A randomized, controlled trial. Ann. Intern. Med. 132, 425-434 (2000).

69. Olschewski, H. et al. Aerosolized prostacyclin and iloprost in severe pulmonary hypertension. Ann. Intern. Med. 124, 820-824 (1996).

70. Olschewski, H. et al. Inhaled iloprost to treat severe pulmonary hypertension. An uncontrolled trial. German PPH Study Group. Ann. Intern. Med. 132, 435-443 (2000).

71. Olschewski, H. et al. Inhaled iloprost for severe pulmonary hypertension. N. Engl. J. Med. 347, 322329 (2002).

72. Olschewski, H. et al. Pharmacodynamics and pharmacokinetics of inhaled iloprost, aerosolized by three different devices, in severe pulmonary hypertension. Chest 124, 1294-1304 (2003).

73. Channick, R. et al. Effects of the dual endothelin receptor antagonist bosentan in patients with pulmonary hypertension: a placebo-controlled study. J. Heart Lung Transplant. 20, 262-263 (2001).

74. Rubin, L. J. et al. Bosentan therapy for pulmonary arterial hypertension. N. Engl. J. Med. 346, 896-903 (2002).

75. Bohle, R. M. et al. Cell type-specific mRNA quantitation in non-neoplastic tissues after laser-assisted cell picking. Pathobiology 68, 191-195 (2000).

76. German, Z. et al. Molecular basis of cell-specific endothelial nitric-oxide synthase expression in airway epithelium. J. Biol. Chem. 275, 8183-8189 (2000).

77. Ide, $\mathrm{H}$ et al. Regulation of pulmonary circulation by alveolar oxygen tension via airway nitric oxide. $J$. Appl. Physiol. 87, 1629-1636 (1999).

78. Grimminger, F., Spriestersbach, R., Weissmann, N. Walmrath, D. \& Seeger, W. Nitric oxide generation and hypoxic vasoconstriction in buffer-perfused rabbit lungs. J. Appl. Physiol. 78, 1509-1515 (1995). Interesting experimental work addressing the importance of lung nitric oxide production in the mediation of hypoxic pulmonary vasoconstriction

79. Ghofrani, H. A. et al. Nitric oxide pathway and phosphodiesterase inhibitors in pulmonary arterial hypertension. J. Am. Coll. Cardiol. 43, 68S-72S (2004).

80. Weissmann, N. et al. Nitric oxide (NO)-dependent but not $\mathrm{NO}$-independent guanylate cyclase activation attenuates hypoxic vasoconstriction in rabbit lungs. Am. J. Respir. Cell Mol. Biol. 23, 222-227 (2000)

81. Schulz, R. et al. Decreased plasma levels of nitric oxide derivatives in obstructive sleep apnoea: response to CPAP therapy. Thorax 55, 1046-1051 (2000).

82. Spriestersbach, R., Grimminger, F., Weissmann, N., Walmrath, D. \& Seeger, W. On-line measurement of nitric oxide generation in buffer-perfused rabbit lungs. J. Appl. Physiol. 78, 1502-1508 (1995).

83. Michelakis, E. D. The role of the NO axis and its therapeutic implications in pulmonary arterial hypertension. Heart Fail. Rev. 8, 5-21 (2003)

84. Ahn, H. S., Foster, M., Cable, M., Pitts, B. J. \& Sybertz, E. J. Ca/CaM-stimulated and cGMP-specific phosphodiesterases in vascular and non-vascular tissues. Adv. Exp. Med. Biol. 308, 191-197 (1991).

85. Fink, T. L., Francis, S. H., Beasley, A., Grimes, K. A. \& Corbin, J. D. Expression of an active, monomeric catalytic domain of the CGMP-binding CGMP-specific phosphodiesterase (PDE5). J. Biol. Chem. 274, 34613-34620 (1999).

86. Giordano, D., De Stefano, M. E., Citro, G., Modica, A \& Giorgi, M. Expression of cGMP-binding cGMPspecific phosphodiesterase (PDE5) in mouse tissues and cell lines using an antibody against the enzyme amino-terminal domain. Biochim. Biophys. Acta 1539, 16-27 (2001)

87. Wharton, J. et al. Antiproliferative effects of phosphodiesterase type 5 inhibition in human pulmonary artery cells. Am. J. Respir. Crit. Care Med. 172, 105-113 (2005). 
Experimental study providing evidence for the antiproliferative effects of sildenafil in human pulmonary artery cells.

88. Corbin, J. D., Beasley, A., Blount, M. A. \& Francis, S. $\mathrm{H}$. High lung PDE5: A strong basis for treating pulmonary hypertension with PDE5 inhibitors. Biochem. Biophys. Res. Commun. 334, 930-938 (2005).

Notable work that explains on a cellular and molecular level the selectivity of PDE5 inhibitors for the pulmonary circulation.

89. Haynes, J., Jr., Kithas, P. A., Taylor, A. E. \& Strada, S. J. Selective inhibition of cGMP-inhibitable cAMP phosphodiesterase decreases pulmonary vasoreactivity. Am. J. Physiol. 261, H487-H492 (1991).

90. Braner, D. A., Fineman, J. R., Chang, R. \& Soifer, S. J. $M \& B$ 22948, a cGMP phosphodiesterase inhibitor, is a pulmonary vasodilator in lambs. Am. J. Physiol. 264, H252-H258 (1993).

91. Cohen, A. H. et al. Inhibition of cyclic 3'-5'-guanosine monophosphate-specific phosphodiesterase selectively vasodilates the pulmonary circulation in chronically hypoxic rats. J. Clin. Invest. 97, 172-179 (1996).

92. Zhao, L. et al. Sildenafil inhibits hypoxia-induced pulmonary hypertension. Circulation 104, 424-428 (2001).

93. Zhao, L., Mason, N. A., Strange, J. W., Walker, H. \& Wilkins, M. R. Beneficial effects of phosphodiesterase 5 inhibition in pulmonary hypertension are influenced by natriuretic Peptide activity. Circulation 107, 234237 (2003).

94. Sebkhi, A., Strange, J. W., Phillips, S. C., Wharton, J. $\&$ Wilkins, M. R. Phosphodiesterase type 5 as a target for the treatment of hypoxia-induced pulmonary hypertension. Circulation 107 3230-3235 (2003).

95. Hanson, K. A. et al. Chronic pulmonary hypertension increases fetal lung cGMP phosphodiesterase activity. Am. J. Physiol. 275, L931-L941 (1998).

96. Nangle, M. R., Cotter, M. A. \& Cameron, N. E. An in vitro study of corpus cavernosum and aorta from mice lacking the inducible nitric oxide synthase gene. Nitric Oxide 9, 194-200 (2003).

97. Bloch, W. et al. Evidence for the involvement of endothelial nitric oxide synthase from smooth muscle cells in the erectile function of the human corpus cavernosum. Urol. Res. 26, 129-135 (1998).

98. Itoh, T. et al. A combination of oral sildenafil and beraprost ameliorates pulmonary hypertension in rats. Am. J. Respir. Crit. Care Med. 169, 34-38 (2004).

99. Schermuly, R. T. et al. Chronic sildenafil treatment inhibits monocrotaline-induced pulmonary hypertension in rats. Am. J. Respir. Crit. Care Med. 169, 39-45 (2004).

100. Sitbon, O. et al. Inhaled nitric oxide as a screening agent for safely identifying responders to oral calcium channel blockers in primary pulmonary hypertension [see comments]. Eur. Respir. J. 12, 265-270 (1998).

101. Rossaint, R. et al. Inhaled nitric oxide for the adult respiratory distress syndrome. N. Engl. J. Med. 328 , 399-405 (1993)

Milestone work reporting the first therapeutic use of inhaled nitric oxide to treat acute pulmonary hypertension and gas-exchange disturbances in acute respiratory distress syndrome patients.

102. Atz, A. M. \& Wessel, D. L. Sildenafil ameliorates effects of inhaled nitric oxide withdrawal.

Anesthesiology 91, 307-310 (1999).

First report of the use of sildenafil in human pulmonary hypertension to facilitate weaning from inhaled nitric oxide in paediatric patients.

103. Prasad, S., Wilkinson, J. \& Gatzoulis, M. A. Sildenafil in primary pulmonary hypertension. N. Engl. J. Med. 343, 1342 (2000)

First case report on the successful long-term therapy of one adult patient with severe idiopathic pulmonary arterial hypertension with oral sildenafil.

104. Abrams, D., Schulze-Neick, I. \& Magee, A. G. Sildenafil as a selective pulmonary vasodilator in childhood primary pulmonary hypertension. Heart $\mathbf{8 4}$, E4 (2000).

105. Patole, S. \& Travadi, J. Sildenafil for 'blue babies'. Ethics, conscience, and science have to be balanced against limited resources. BMJ 325, 1174 (2002).

106. Oliver, J. \& Webb, D. J. Sildenafil for 'blue babies' Such unlicensed drug use might be justified as last resort. BMJ 325, 1174 (2002).
107. Ghofrani, H. A. et al. Combination therapy with oral sildenafil and inhaled iloprost for severe pulmonary hypertension. Ann. Intern. Med. 136, 515-522 (2002).

First large clinical trial assessing the acute haemodynamic effects of sildenafil as compared with inhaled nitric oxide, inhaled iloprost or combinations of sildenafil and iloprost.

108. Wilkens, H. et al. Effect of inhaled iloprost plus oral sildenafil in patients with primary pulmonary hypertension. Circulation 104, 1218-1222 (2001).

109. Kothari, S. S. \& Duggal, B. Chronic oral sildenafil therapy in severe pulmonary artery hypertension. Indian Heart J. 54, 404-409 (2002).

110. Sastry, B. K. et al. A study of clinical efficacy of sildenafil in patients with primary pulmonary hypertension. Indian Heart J. 54, 410-414 (2002).

111. Sastry, B. K., Narasimhan, C., Reddy, N. K. \& Raju, B. S. Clinical efficacy of sildenafil in primary pulmonary hypertension: a randomized, placebo-controlled, double-blind, crossover study. J. Am. Coll. Cardiol. 43 1149-1153 (2004)

112. Ghofrani, H. A. et al. Oral sildenafil as long-term adjunct therapy to inhaled iloprost in severe pulmonary arterial hypertension. J. Am. Coll. Cardiol. 42, 158-164 (2003).

The first report of the successful long-term use of a combination therapy in patients with severe pulmonary hypertension.

113. Watanabe, H. et al. Sildenafil for primary and secondary pulmonary hypertension. Clin. Pharmacol. Ther. 71, 398-402 (2002).

114. Zimmermann, A. T., Calvert, A. F. \& Veitch, E. M. Sildenafil improves right-ventricular parameters and quality of life in primary pulmonary hypertension. Intern. Med. J. 32, 424-426 (2002).

115. Singh, B. et al. Sildenafil in the management of primary pulmonary hypertension. Indian Heart J. $\mathbf{5 4}$ 297-300 (2002)

116. Lepore, J. J. et al. Effect of sildenafil on the acute pulmonary vasodilator response to inhaled nitric oxide in adults with primary pulmonary hypertension. $\mathrm{Am}$. J. Cardiol. 90, 677-680 (2002)

117. Michelakis, E. et al. Oral sildenafil is an effective and specific pulmonary vasodilator in patients with pulmonary arterial hypertension: comparison with inhaled nitric oxide. Circulation 105, 2398-2403 (2002).

118. Carlsen, J., Kjeldsen, K. \& Gerstoft, J. Sildenafil as a successful treatment of otherwise fatal HIV-related pulmonary hypertension. AIDS 16, 1568-1569 (2002)

119. Schumacher, Y. O., Zdebik, A., Huonker, M. \& Kreisel, W. Sildenafil in HIV-related pulmonary hypertension. AIDS 15, 1747-1748 (2001).

120. Ghofrani, H. A. et al. Sildenafil for long-term treatment of nonoperable chronic thromboembolic pulmonary hypertension. Am. J. Respir. Crit. Care Med. 167 1139-1141 (2003).

121. Galie, N. et al. Sildenafil citrate therapy for pulmonary arterial hypertension. N. Engl. J. Med. 353, 21482157 (2005)

Report on the pivotal randomized controlled trial which resulted in the final approval of oral sildenafil for the treatment of pulmonary arterial hypertension.

122. Moncada, I., Jara, J., Subira, D., Castano, I. \& Hernandez, C. Efficacy of sildenafil citrate at 12 hours after dosing: re-exploring the therapeutic window. Eur. Urol. 46, 357-360 (2004)

123. Mullershausen, F. et al. Direct activation of PDE5 by cGMP: long-term effects within NO/cGMP signaling. J. Cell Biol. 160, 719-727 (2003).

124. Francis, S. H. et al. Ligand-induced conformational changes in cyclic nucleotide phosphodiesterases and cyclic nucleotide-dependent protein kinases. Methods 14, 81-92 (1998)

125. Gopal, V. K., Francis, S. H. \& Corbin, J. D. Allosteric sites of phosphodiesterase-5 (PDE5). A potential role in negative feedback regulation of cGMP signaling in corpus cavernosum. Eur. J. Biochem. 268, 33043312 (2001)

126. Corbin, J. D. \& Francis, S. H. Pharmacology of phosphodiesterase-5 inhibitors. Int. J. Clin. Pract. 56, 453-459 (2002)

127. Huai, Q., Liu, Y., Francis, S. H., Corbin, J. D. \& Ke, H. Crystal structures of phosphodiesterases 4 and 5 in complex with inhibitor 3-isobutyl-1-methylxanthine suggest a conformation determinant of inhibitor selectivity. J. Biol. Chem. 279, 13095-13101 (2004)
128. Michelakis, E. D. et al. Long-term treatment with ora sildenafil is safe and improves functional capacity and hemodynamics in patients with pulmonary arterial hypertension. Circulation 108, 2066-2069 (2003).

129. CELORIA, G. C., FRIEDELL, G. H. \& SOMMERS, S. C. Raynaud's disease and primary pulmonary hypertension. Circulation 22, 1055-1059 (1960).

130. SMITH, W. M. $\&$ KROOP, I. G. Raynaud's disease in primary pulmonary hypertension. JAMA $165,1245-$ 1248 (1957)

131. D'Alonzo, G. E. et al. Survival in patients with primary pulmonary hypertension. Results from a national prospective registry. Ann. Intern. Med. 115, 343-349 (1991).

Milestone report on the natural course of primary pulmonary hypertension based on data from the National Institutes of Health registry. Most currently published studies refer to this report if comparisons to a historic control are required.

132. Kallenberg, C. G. Overlapping syndromes, undifferentiated connective tissue disease, and other fibrosing conditions. Curr. Opin. Rheumatol. 7, 568573 (1995).

133. Pope, J. et al. Iloprost and cisaprost for Raynaud's phenomenon in progressive systemic sclerosis. Cochrane. Database. Syst. Rev. CD000953 (2000).

134. Belch, J. J. \& Ho, M. Pharmacotherapy of Raynaud's phenomenon. Drugs 52, 682-695 (1996).

135. Boin, F. \& Wigley, F. M. Understanding, assessing and treating Raynaud's phenomenon. Curr. Opin. Rheumatol. 17, 752-760 (2005).

136. Kamata, Y., Kamimura, T., Iwamoto, M. \& Minota, S. Comparable effects of sildenafil citrate and alprostadil on severe Raynaud's phenomenon in a patient with systemic sclerosis. Clin. Exp. Dermatol. 30, 451 (2005)

137. Gore, J. \& Silver, R. Oral sildenafil for the treatment of Raynaud's phenomenon and digital ulcers secondary to systemic sclerosis. Ann. Rheum. Dis. 64, 1387 (2005).

138. Rosenkranz, S. et al. Sildenafil improved pulmonary hypertension and peripheral blood flow in a patient with scleroderma-associated lung fibrosis and the raynaud phenomenon. Ann. Intern. Med. 139, 871873 (2003).

139. Lichtenstein, J. R. Use of sildenafil citrate in Raynaud's phenomenon: comment on the article by Thompson et al. Arthritis Rheum. 48, 282-283 (2003).

140. Fries, R., Shariat, K., von, W. H. \& Bohm, M. Sildenafil in the treatment of Raynaud's phenomenon resistant to vasodilatory therapy. Circulation 112, 2980-2985 (2005).

Original report of the first randomized controlled trial proving the efficacy of sildenafil to treat Raynauds's phenomenon.

141. Maurice, D. H. et al. Cyclic nucleotide phosphodiesterase activity, expression, and targeting in cells of the cardiovascular system. Mol. Pharmacol. 64, 533-546 (2003)

142. Agusti, A. G. \& Rodriguez-Roisin, R. Effect of pulmonary hypertension on gas exchange. Eur. Respir. J. 6, 1371-1377 (1993)

143. Ghofrani, H. A. et al. Sildenafil for treatment of lung fibrosis and pulmonary hypertension: a randomised controlled trial. Lancet 360, 895-900 (2002). The first clinical study to show that an oral vasodilator (sildenafil) can improve gas exchange, with comparable effects to those achievable with inhaled nitric oxide.

144. Ghofrani, H. A. et al. Sildenafil increased exercise capacity during hypoxia at low altitudes and at Mount Everest base camp: a randomized, double-blind, placebo-controlled crossover trial. Ann. Intern. Med. 141, 169-177 (2004).

This randomized controlled trial proved for the first time that effective treatment of hypoxic pulmonary hypertension with sildenafil results in improvements of exercise ability and right heart function under such conditions.

145. Richalet, J. P. et al. Sildenafil inhibits altitudeinduced hypoxemia and pulmonary hypertension. Am. J. Respir. Crit. Care Med. 171, 275-281 (2005).

146. Hsu, A. R. et al. Sildenafil improves cardiac output and exercise performance during acute hypoxia, but not normoxia. J. Appl. Physiol.(2006).

147. Naeije, R. Pulmonary hypertension and right heart failure in chronic obstructive pulmonary disease. Proc Am. Thorac. Soc. 2, 20-22 (2005).

148. Higenbottam, T. Pulmonary hypertension and chronic obstructive pulmonary disease: a case for treatment. Proc. Am. Thorac. Soc. 2, 12-19 (2005). 
149. Voelkel, N. F. \& Cool, C. D. Pulmonary vascular involvement in chronic obstructive pulmonary disease. Eur. Respir. J. Suppl. 46, 28s-32s (2003).

150. Barbera, J. A., Peinado, V. I. \& Santos, S. Pulmonary hypertension in chronic obstructive pulmonary disease. Eur. Respir. J. 21, 892-905 (2003).

151. Alp, S., Skrygan, M., Schmidt, W. E. \& Bastian, A Sildenafil improves hemodynamic parameters in COPD-an investigation of six patients. Pulm Pharmacol. Ther. (2005).

152. Jessup, M. \& Brozena, S. Heart failure. N. Engl. J. Med. 348, 2007-2018 (2003).

153. Anversa, P. et al. Ischemic cardiomyopathy: myocyte cell loss, myocyte cellular hypertrophy, and myocyte cellular hyperplasia. Ann. NY Acad. Sci. 752, 47-64 (1995).

154. Anversa, P., Capasso, J. M., Olivetti, G. \& Sonnenblick, E. H. Cellular basis of ventricular remodeling in hypertensive cardiomyopathy. $\mathrm{Am}$. J. Hypertens. 5, 758-770 (1992).

155. Kasimir, M. T. et al. Reverse cardiac remodelling in patients with primary pulmonary hypertension afte isolated lung transplantation. Eur. J. Cardiothorac. Surg. 26, 776-781 (2004).

156. Wilkins, M. R. et al. Sildenafil versus Endothelin Receptor Antagonist for Pulmonary Hypertension (SERAPH) Study. Am. J. Respir. Crit. Care Med. 171, 1292-1297 (2005).

157. Kentera, D. \& Susic, D. Dynamics of regression of right ventricular hypertrophy in rats with hypoxic pulmonary hypertension. Respiration 39, 272-275 (1980).

158. Rich, S. \& Brundage, B. H. High-dose calcium channelblocking therapy for primary pulmonary hypertension: evidence for long-term reduction in pulmonary arteria pressure and regression of right ventricular hypertrophy. Circulation 76, 135-141 (1987).

159. Pelouch, V. et al. Regression of chronic hypoxiainduced pulmonary hypertension, right ventricular hypertrophy, and fibrosis: effect of enalapril. Cardiovasc. Drugs Ther. 11, 177-185 (1997)

160. O'Blenes, S. B., Fischer, S., Mclntyre, B., Keshavjee, S $\&$ Rabinovitch, M. Hemodynamic unloading leads to regression of pulmonary vascular disease in rats. $J$. Thorac. Cardiovasc. Surg. 121, 279-289 (2001).

161. Takimoto, E. et al. Chronic inhibition of cyclic GMP phosphodiesterase $5 \mathrm{~A}$ prevents and reverses cardiac hypertrophy. Nature Med. 11, 214-222 (2005).

Milestone work highlighting the importance of PDE5 in the course of myocardial hypertrophy and the potential of the PDE5 inhibitor sildenafil as an antihypertrophic treatment.

162. Hassan, M. A. \& Ketat, A. F. Sildenafil citrate increases myocardial cGMP content in rat heart, decreases its hypertrophic response to isoproterenol and decreases myocardial leak of creatine kinase and troponin T. BMC Pharmacol. 5, 10 (2005)

163. Katz, S. D. et al. Efficacy and safety of sildenafil citrate in men with erectile dysfunction and chronic heart failure. Am. J. Cardiol. 95, 36-42 (2005).

164. Lepore, J. J. et al. Hemodynamic effects of sildenafil in patients with congestive heart failure and pulmonary hypertension: combined administration with inhaled nitric oxide. Chest 127, 1647-1653 (2005).

165. Hirata, K., Adji, A., Vlachopoulos, C. \& O'rourke, M. F. Effect of Sildenafil on Cardiac Performance in Patients With Heart Failure. Am. J. Cardiol. 96, 1436-1440 (2005).

166. Freitas, D., Athanazio, R., Almeida, D., Dantas, N. \& Reis, F. Sildenafil improves quality of life in men with heart failure and erectile dysfunction. Int. J. Impot. Res. 18, 210-212 (2006)

167. Fisher, P. W., Salloum, F., Das, A., Hyder, H. \& Kukreja, R. C. Phosphodiesterase- 5 inhibition with sildenafil attenuates cardiomyocyte apoptosis and left ventricular dysfunction in a chronic model of doxorubicin cardiotoxicity. Circulation 111, 16011610 (2005).

168. Webster, L. J., Michelakis, E. D., Davis, T. \& Archer, S. L. Use of sildenafil for safe improvement of erectile function and quality of life in men with New York Heart Association classes II and III congestive heart failure: a prospective, placebo-controlled, double-blind crossover trial. Arch. Intern. Med. 164, 514-520 (2004).
169. Alaeddini, J. et al. Efficacy and safety of sildenafil in the evaluation of pulmonary hypertension in severe heart failure. Am. J. Cardiol. 94, 1475-1477 (2004).

170. Guazzi, M., Tumminello, G., Di, M. F., Fiorentini, C. \& Guazzi, M. D. The effects of phosphodiesterase-5 inhibition with sildenafil on pulmonary hemodynamics and diffusion capacity, exercise ventilatory efficiency, and oxygen uptake kinetics in chronic heart failure. $J$. Am. Coll. Cardiol. 44, 2339-2348 (2004)

171. Mickley, H. \& Poulsen, T. S. Use of sildenafil is safe in men with congestive heart failure Arch. Intern. Med. 164, 2068 (2004)

172. Mikhail, N. Efficacy and safety of sildenafil in patients with congestive heart failure. Arch. Intern. Med. 164 2067-2068 (2004).

173. Prickaerts, J. et al. Effects of two selective phosphodiesterase type 5 inhibitors, sildenafil and vardenafil, on object recognition memory and hippocampal cyclic GMP levels in the rat. Neuroscience 113, 351-361 (2002)

174. Blokland, A., Prickaerts, J., Honig, W. \& de Vente, J. State-dependent impairment in object recognition after hippocampal NOS inhibition. Neuroreport 9 4205-4208 (1998)

175. Kruuse, C. Thomsen, L. L., Jacobsen, T. B. \& Olesen, $J$. The phosphodiesterase 5 inhibitor sildenafil has no effect on cerebral blood flow or blood velocity, but nevertheless induces headache in healthy subjects. $J$. Cereb. Blood Flow Metab. 22, 1124-1131 (2002).

176. Arnavaz, A. et al. Effect of sildenafil (Viagra) on cerebral blood flow velocity: a pilot study. Psychiatry Res. 122, 207-209 (2003).

177. Kruuse, C., Thomsen, L. L., Birk, S. \& Olesen, J. Migraine can be induced by sildenafil without changes in middle cerebral artery diameter. Brain $126,241-247$ (2003)

178. Rosengarten, B., Huwendiek, O. \& Kaps, M. Neurovascular coupling and cerebral autoregulation can be described in terms of a control system. Ultrasound Med. Biol. 27, 189-193 (2001).

179. Rosengarten, B., Osthaus, S. \& Kaps, M. Doppler investigation of within-session reproducibility in a visual stimulation task to assess the volunteer-dependent variation. Cerebrovasc. Dis. 16, 53-60 (2003)

180. Zonta, $\mathrm{M}$ et al Neuron-to-astrocyte signaling is central to the dynamic control of brain microcirculation. Nature Neurosci. 6, 43-50 (2003).

181. Sette, G. et al. Local brain haemodynamics and oxygen metabolism in cerebrovascular disease. Positron emission tomography. Brain 112 (Pt 4), 931-951 (1989).

182. Ito, H., Kanno, I., Takahashi, K., Ibaraki, M. \& Miura S. Regional distribution of human cerebral vascular mean transit time measured by positron emission tomography. Neuroimage 19, 1163-1169 (2003).

183. Kidwell, C. S., Villablanca, J. P. \& Saver, J. L. Advances in neuroimaging of acute stroke. Curr. Atheroscler. Rep. 2, 126-135 (2000)

184. Lang, C. J. The use of neuroimaging techniques for clinical detection of neurotoxicity: a review. Neurotoxicology 21, 847-855 (2000)

185. Inoha, S. et al. Type V phosphodiesterase expression in cerebral arteries with vasospasm after subarachnoid hemorrhage in a canine model. Neurol. Res. 24, 607-612 (2002).

186. Zhang, R. et al. Nitric oxide enhances angiogenesis via the synthesis of vascular endothelial growth factor and cGMP after stroke in the rat. Circ. Res. 92, 308-313 (2003).

Elegant work describing the importance of nitric oxide and cGMP in cerebral repair after stroke injury.

187. Buerk, D. G., Ances, B. M., Greenberg, J. H. \& Detre, J. A. Temporal dynamics of brain tissue nitric oxide during functional forepaw stimulation in rats. Neuroimage 18, 1-9 (2003)

188. Rosengarten, B. et al. Sildenafil Improves Dynamic Vascular Function in the Brain: Studies in Patients with Pulmonary Hypertension. Cerebrovasc. Dis. 21, 194200 (2005)

First clinical study showing improvements in microvascular dynamic adaptation of blood flow to regional neuronal activity (demand-dependent perfusion) in the brain following sildenafil administration.
189. Wang, L., Gang, Z. Z., Lan, Z. R. \& Chopp, M. Activation of the PI3-K/Akt pathway mediates cGMP enhanced-neurogenesis in the adult progenitor cells derived from the subventricular zone. J. Cereb. Blood Flow Metab. 25, 1150-1158 (2005).

90. Musicki, B. et al. Erection capability is potentiated by long-term sildenafil treatment: role of blood flowinduced endothelial nitric-oxide synthase phosphorylation. Mol. Pharmacol. 68, 226-232 (2005). Intriguing investigation suggesting a new mechanistic explanation for the long-term effects induced by sildenafil treatment, which differ from short-term vasodilatory effects of the same drug.

191. Francis, S. H., Turko, I. V. \& Corbin, J. D. Cyclic nucleotide phosphodiesterases: relating structure and function. Prog. Nucleic Acid Res. Mol. Biol. 65, 1-52 (2001).

192. Fawcett, L. et al. Molecular cloning and characterization of a distinct human phosphodiesterase gene family: PDE11A. Proc. Natl Acad. Sci. USA 97, 3702-3707 (2000)

193. Beavo, J. A. Cyclic nucleotide phosphodiesterases: functional implications of multiple isoforms. Physio Rev. 75, 725-748 (1995) Excellent overview of PDEs and their functional implications by one of the most renowned scientists in this field.

194. Dousa, T. P. Cyclic-3',5'-nucleotide phosphodiesterase isozymes in cell biology and pathophysiology of the kidney. Kidney Int. 55, 29-62 (1999).

195. Hayashi, M. et al. Molecular cloning and characterization of human PDE8B, a novel thyroidspecific isozyme of $3^{\prime}, 5^{\prime}$-cyclic nucleotide phosphodiesterase. Biochem. Biophys. Res. Commun 250, 751-756 (1998).

196. Soderling, S. H., Bayuga, S. J. \& Beavo, J. A. Cloning and characterization of a cAMP-specific cyclic nucleotide phosphodiesterase. Proc. Natl Acad. SCi. USA 95, 8991-8996 (1998)

197. Yang, Q. et al. A novel cyclic GMP stimulated phosphodiesterase from rat brain. Biochem. Biophys. Res. Commun. 205, 1850-1858 (1994).

198. Pyne, N. J. \& Furman, B. L. Cyclic nucleotide phosphodiesterases in pancreatic islets. Diabetologia 46, 1179-1189 (2003)

199. Glavas, N. A., Ostenson, C., Schaefer, J. B. Vasta, V. \& Beavo, J. A. T cell activation up-regulates cyclic nucleotide phosphodiesterases $8 \mathrm{~A} 1$ and 7A3. Proc. Natl Acad. Sci. USA 98, 6319-6324 (2001).

200. Brown, D. G et al. Crystal structures of human phosphodiesterase 5 and its ligand complex and their use in the design of site-directed mutants and design or screening of inhibitor compounds. World Patent 2003038080 (2003)

201. Brown, D. G. et al. Crystal structures of human phosphodiesterase- 5 and its ligand complex and their use in the design of site-directed mutants and design or screening of inhibitor compounds. World Patent 2004097010 (2004)

\section{Acknowledgements}

Our gratitude goes to R. Schermuly, N. Weissmann and R. Morty (from the University of Giessen Lung Center (UGLC) and to G. Butrous, D. Brown and C. Wayman (from Pfizer Ltd., Sandwich) for thorough linguistic editing helpful comments and input to the manuscript. This work was supported by the German research foundation (DFG; Sonderforschungsbereich 547)

\section{Competing interests statement}

The authors declare competing financial interests: see Web version for details.

DATABASES

The following terms in this article are linked online to: Entrez Gene: http://www.ncbi.nlm.nih.gov/entrez/query. fcgi?db=gene eNOS | PDE2 | PDE3 | PDE4 |PDE5 |PDE6 